\title{
C-GLORSv5: an improved multipurpose global ocean eddy-permitting physical reanalysis
}

\author{
Andrea Storto ${ }^{1}$ and Simona Masina ${ }^{1,2}$ \\ ${ }^{1}$ Centro Euro-Mediterraneo sui Cambiamenti Climatici, 40128 Bologna, Italy \\ ${ }^{2}$ Istituto Nazionale di Geofisica e Vulcanologia, 40128 Bologna, Italy \\ Correspondence to: Andrea Storto (andrea.storto@cmcc.it) \\ Received: 4 August 2016 - Published in Earth Syst. Sci. Data Discuss.: 10 August 2016 \\ Revised: 10 November 2016 - Accepted: 11 November 2016 - Published: 29 November 2016
}

\begin{abstract}
Global ocean reanalyses combine in situ and satellite ocean observations with a general circulation ocean model to estimate the time-evolving state of the ocean, and they represent a valuable tool for a variety of applications, ranging from climate monitoring and process studies to downstream applications, initialization of long-range forecasts and regional studies. The purpose of this paper is to document the recent upgrade of C-GLORS (version 5), the latest ocean reanalysis produced at the Centro Euro-Mediterraneo per i Cambiamenti Climatici (CMCC) that covers the meteorological satellite era (1980-present) and it is being updated in delayed time mode. The reanalysis is run at eddy-permitting resolution $\left(1 / 4^{\circ}\right.$ horizontal resolution and 50 vertical levels) and consists of a three-dimensional variational data assimilation system, a surface nudging and a bias correction scheme. With respect to the previous version (v4), C-GLORSv5 contains a number of improvements. In particular, background- and observation-error covariances have been retuned, allowing a flow-dependent inflation in the globally averaged background-error variance. An additional constraint on the Arctic sea-ice thickness was introduced, leading to a realistic ice volume evolution. Finally, the bias correction scheme and the initialization strategy were retuned. Results document that the new reanalysis outperforms the previous version in many aspects, especially in representing the variability of global heat content and associated steric sea level in the last decade, the top $80 \mathrm{~m}$ ocean temperature biases and root mean square errors, and the Atlantic Ocean meridional overturning circulation; slight worsening in the high-latitude salinity and deep ocean temperature emerge though, providing the motivation for further tuning of the reanalysis system. The dataset is available in NetCDF format at doi:10.1594/PANGAEA.857995.
\end{abstract}

\section{Introduction}

Ocean retrospective analyses (or simply, reanalyses, or ocean syntheses) combine available in situ and satellite observations with an ocean general circulation model (OGCM) forced by atmospheric reanalyses by means of advanced data assimilation techniques, with the aim of estimating the state of the ocean in the past few decades (Balmaseda et al., 2015). Such a method implicitly ingests not only the information that comes from the global ocean observing system, but also the global meteorological observing system through the atmospheric forcing, and our knowledge of the ocean physics and dynamics through the OGCM.
Production of ocean reanalyses was originally fostered by the need to monitor the climate change signature on the ocean, for instance in terms of heat content evolution (Carton and Santorelli, 2008). Additionally, long-term (e.g. seasonal, decadal) prediction systems require proper initial conditions for the ocean, because of the dominant effect of the ocean initial conditions on the predictability over long timescales (e.g. Balmaseda and Anderson, 2009). For this reason, ocean reanalyses are a crucial requirement for climate predictions, which further encourages the improved use of observations along time. Reanalyses can be produced either in delayed or near real-time mode. The former mode refers to the production and update process that is generally performed, occasionally when all reprocessed input observation datasets 
are available; while the latter refers to a continuous update process, possibly using real-time observations, generally adopted when the reanalysis serves the purpose of initializing an operational long-range prediction system (e.g. Zuo et al., 2016).

During the last decade, the maturity of ocean reanalyses has been shown through many validation studies (Stammer et al., 2010; Xue et al., 2012; Storto et al., 2016c), which supported the idea that reanalyses provide useful information at least for the upper ocean (top $700 \mathrm{~m}$ ). Meanwhile, the ocean observing system has notably evolved with the implementation of the Argo floats network, thanks to which an unprecedented sampling of the subsurface temperature and salinity was achieved.

Regional ocean simulations or analysis systems need open boundary conditions at the domain boundaries, which may be provided by ocean reanalyses (e.g. Sotillo et al., 2015). Additionally, downstream applications (e.g. biogeochemical, fishery and larval dispersal models) require physical fields as input, preferably from an ocean reanalysis (e.g. Lazzari et al., 2012; Meliá et al., 2013).

Improvements in ocean reanalyses are also required in the context of producing Earth system reanalyses for the atmosphere and ocean. "Strongly coupled" data assimilation methods are active research topics that will likely improve the use of observations for a variety of applications such as short- and long-term predictions (Laloyaux et al., 2015) and climate reanalyses (e.g. Dee et al., 2014). This implies that the optimal configuration of ocean retrospective analyses will benefit not only ocean applications, strictly speaking, but also Earth system assimilative experiments.

All the applications listed above clearly motivate developments and production of ocean reanalyses with possibly short delays of dissemination beyond real time. The Fondazione CMCC (Centro Euro-Mediterraneo sui Cambiamenti Climatici) has devoted efforts in the last decade to build a stateof-the-art ocean physical reanalysis system. First reanalyses were produced at relatively coarse resolution (about $2^{\circ}$ ) with the assimilation of hydrographic profiles only through an optimal interpolation scheme (Bellucci et al., 2007; Masina et al., 2011). Since then, the data assimilation system has been upgraded to a three-dimensional variational scheme that allowed the assimilation of altimetry and remotely sensed data (Storto et al., 2011, 2013). The system has then been extensively validated and retuned, especially in the formulation and estimation of background-error covariances (Storto et al., 2014). Fostered by the European Union funded MyOcean project and its follow-ups (Masina et al., 2016), the resolution of the CMCC reanalysis system (called C-GLORS hereafter, i.e. the CMCC Global Ocean Reanalysis System) has been increased to the eddy-permitting resolution (approximately $1 / 4^{\circ}$ on the horizontal), as documented by Storto et al. (2016a) and has been used in a variety of different studies on the global ocean, ranging from semi-enclosed seas characterization (Cessi et al., 2014), to decadal studies on the At- lantic Ocean circulation and heat budget (Ezer, 2015; Yang et al., 2016a), and energy budget analysis in the Arctic region (Mayer et al., 2016).

C-GLORS was released through the MyOcean portal (now at http://marine.copernicus.eu) in 2010, and has been upgraded with time. Masina et al. (2016) have cross-compared the four global ocean reanalyses produced in the framework of the MyOcean project, showing that C-GLORSv4 is a stateof-the-art reanalysis as it compares very well with other reanalyses and validating datasets, at least for the parameters investigated in the aforementioned comparison (i.e. sea surface temperature and salinity, averaged temperature in the layers $0-800$ and $0-2000 \mathrm{~m}$, sea-ice concentration, Atlantic meridional overturning circulation at $2^{\circ} \mathrm{N}$ and volume transports in selected transects). Starting from these results, the aim of this paper is to describe and assess the improvements present in the latest version of C-GLORS released (v5) and compare it with its predecessor.

The article is structured as follows: Sect. 2 describes the reanalysis system focussing on the changes with respect to C-GLORSv4. Section 3 presents selected results on the improvements borne by the latest version. Section 4 summarizes and discusses the main achievements. The Appendix presents in detail the reanalysis data product. Version 5 of C-GLORS will be updated in delayed time mode, typically with an approximate 1-year delay beyond present time due to the dissemination of quality-checked observational data.

\section{C-GLORS reanalysis system}

In this section we briefly describe the reanalysis system, with the aim of highlighting the changes with respect to version 4 . A detailed description of the reanalysis system for $\mathrm{v} 4$ is available in Storto et al. (2016a). Storto et al. (2014) also describe the choices for background-error covariances in C-GLORS.

\subsection{General description}

The reanalysis spans the period 1979-2015, although data are released from 1980 onwards as the first year is affected by an initial adjustment. The reanalysis system includes a (i) three-dimensional variational data assimilation scheme called OceanVar (see next section) that assimilates hydrographic profiles from the UK Met Office Hadley Centre EN3 dataset (ENACT/ENSEMBLES, version 3) (Ingleby and Huddleston, 2007) until 2012 and EN4 dataset (Good et al., 2013) afterwards, and along-track altimetric observations provided by AVISO following Storto et al. (2011); (ii) the NEMO ocean model (Madec, 2008), configured at about $1 / 4^{\circ}$ resolution using a tripolar grid, with 50 vertical depth levels and partial steps (Barnier et al., 2006) and coupled to the LIM2 sea-ice model (Louvain-la-Neuve Sea Ice Model, Fichefet and Morales Maqueda, 1997) with elasto-viscoplastic (EVP) sea-ice rheology (Bouillon et al., 2009); (iii) a nudging scheme that assimilates space-bourne 
sea-surface temperature observations supplied by NOAA (Reynolds et al., 2007) and sea-ice data; and (iv) a large-scale bias correction (LSBC) scheme that corrects the model tendencies to limit the large scale biases induced by systematic errors of the NEMO model parameterizations and the atmospheric forcing.

C-GLORS is forced by the European Centre for MediumRange Weather Forecasts (ECMWF) ERA-Interim atmospheric reanalysis (Dee et al., 2011) using the bulk formulas from Large and Yeager (2004). ERA-Interim provides $3 \mathrm{~h}$ fields of temperature and humidity at $2 \mathrm{~m}$, wind at $10 \mathrm{~m}$, daily mean fields of short- and long-wave radiation, and total and solid precipitation. The short-wave radiation is modulated through the scheme of Bernie et al. (2007) to reproduce its diurnal cycle. Storto et al. (2016a) show the positive contributions of all assimilation components (OceanVar, surface nudging, LSBC) to the performance of C-GLORS. More details on the data assimilation formulation are provided in the next section.

\section{OceanVar data assimilation}

The data assimilation system used in C-GLORS is a threedimensional variational (3DVAR) scheme called OceanVar (Dobricic and Pinardi, 2008; Storto et al., 2014). The assimilation time window is 7 days and the frequency of the assimilation steps is also 7 days. The 3DVAR scheme minimizes a cost function $J$ given with the incremental formulation (i.e. with minimization performed over $\delta \boldsymbol{x}=\boldsymbol{x}-\boldsymbol{x}^{\mathrm{b}}$, with $\boldsymbol{x}$ the ocean state, i.e. the analysis at the minimum of $J$, and $\boldsymbol{x}^{\mathrm{b}}$ the background state):

$$
J(\delta x)=\frac{1}{2} \delta \boldsymbol{x}^{\mathrm{T}} \mathbf{B}^{-1} \boldsymbol{\delta} \boldsymbol{x}+\frac{1}{2}(\mathbf{H} \boldsymbol{\delta} \boldsymbol{x}-\boldsymbol{d})^{\mathrm{T}} \mathbf{R}^{-1}(\mathbf{H} \boldsymbol{\delta} \boldsymbol{x}-\boldsymbol{d}),
$$

where $\mathbf{B}$ and $\mathbf{R}$ are the background- and observation-error covariance matrices, respectively, $\boldsymbol{d}$ is the vector of misfits calculated using the non-linear observation operator, $\mathbf{H}$ is the tangent-linear version of the observation operator. In order to avoid the inversion of $\mathbf{B}$ and precondition the minimization, the cost function is minimized over the space of the control vector $\boldsymbol{v}$, with $\delta \boldsymbol{x}=\mathbf{V} \boldsymbol{v}$ and $\mathbf{B}=\mathbf{V} \mathbf{V}^{\mathrm{T}}$, such that the cost function becomes

$J(v)=\frac{1}{2} \boldsymbol{v}^{\mathrm{T}} \boldsymbol{v}+\frac{1}{2}(\mathbf{H V} \boldsymbol{v}-\boldsymbol{d})^{\mathrm{T}} \mathbf{R}^{-1}(\mathbf{H V} \boldsymbol{v}-\boldsymbol{d})$.

The square-root background-error covariance matrix is decomposed in several operators:

$\mathbf{V}=\mathbf{V}_{\eta} \mathbf{V}_{h} \mathbf{V}_{v}$,

where $\mathbf{V}_{v}$ is the vertical covariance operator, modelled through 10-mode season-dependent multivariate empirical orthogonal functions (EOFs) of temperature and salinity, namely $\mathbf{V}_{v}=\mathbf{U} \boldsymbol{\Lambda}^{1 / 2}$, with $\mathbf{U}$ the matrix containing eigenvectors and $\boldsymbol{\Lambda}$ the diagonal matrix containing eigenvalues. The horizontal operator $\mathbf{V}_{h}$ is modelled through a first-order recursive filter with inhomogeneous correlation length scales (Storto et al., 2014) and $\mathbf{V}_{\eta}$ is the sea level operator that analytically computes the sea level increment from increments of temperature and salinity using a local hydrostatic balance (Storto et al., 2011).

The observation-error covariance matrix is assumed diagonal, i.e. observation errors are assumed independent between any pair of observations. For in situ observations, the error accounts for instrumental accuracy and representativeness error and is defined as a function of the parameter (temperature or salinity), type of observation (bathythermographs, CTDs, floats or moorings), the depth and the location. For sea level anomaly, the error variance accounts for the satellite instrumental accuracy, the mean dynamic topography error (provided by CLS/AVISO) and the representativeness error. Usual climatology and background quality checks are implemented in C-GLORS and described by Storto et al. (2016a).

\subsection{Improvements with respect to the previous version}

We review here the main improvements of C-GLORSv5 with respect to its predecessor C-GLORSv4. The upgrade of the system follows the validation exercise performed with $\mathrm{C}$ GLORSv4, which highlighted the need to solve some deficiencies present in that version. The completion of the new version has also been fostered by the requirements of many users in term of augmented output frequency and variables. Below, we detail the changes for each of the reanalysis components.

\subsubsection{Ocean and sea-ice model}

The NEMO version used for C-GLORSv5 is 3.2. No major differences are implemented in this version of C-GLORS except for a tuning of the turbulent kinetic energy (TKE) vertical mixing closure scheme. Following the work of Calvert and Siddorn (2013) and Megann et al. (2014), values for the background vertical viscosity and diffusivity were increased to $1.2 \times 10^{-4}$ and $1.2 \times 10^{-5} \mathrm{~m}^{2} \mathrm{~s}^{-1}$, respectively, from the original $1.0 \times 10^{-4}$ and $1.0 \times 10^{-5} \mathrm{~m}^{2} \mathrm{~s}^{-1}$, namely the vertical diffusivity and viscosity were increased by $20 \%$. Additionally, the vertical decay of the TKE penetration was restored to a globally uniform value of $10 \mathrm{~m}$, opposed to the previous latitude-dependent formulation, found to deteriorate cold biases and warm biases at mid- and low-latitudes, respectively.

Additionally, C-GLORSv5 no longer includes the ERAInterim forcing correction described in Storto et al. (2012, 2016a). This choice reflects the need to avoid specific postprocessing of the atmospheric forcing, difficult to achieve within near real-time production, along with the idea of preferring the use of atmospheric parameters in balance with each other rather than introducing imbalances due to the correction of radiative fluxes only. 

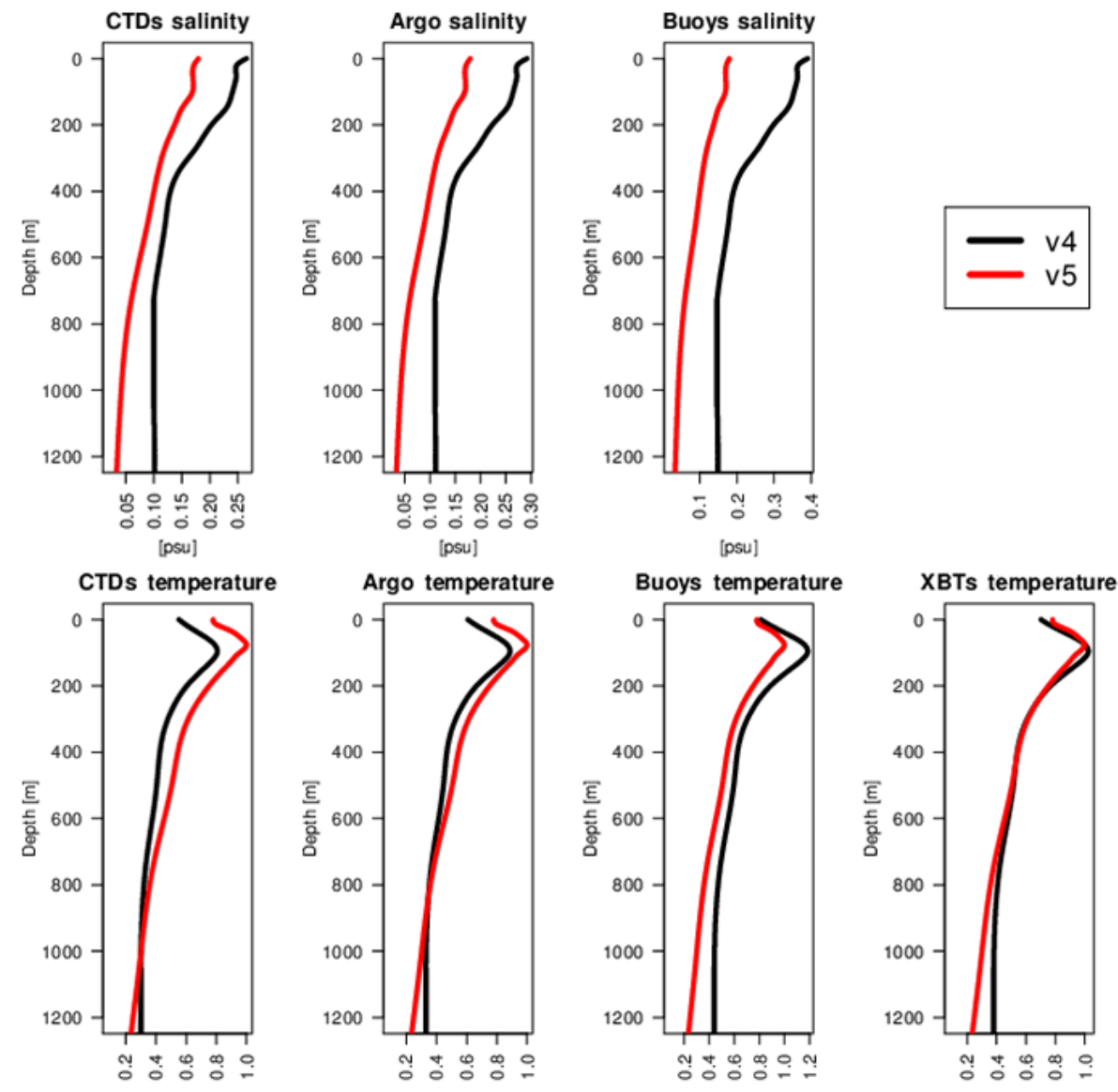

Figure 1. Observation-error profiles for use in the in situ data assimilation in C-GLORSv4 (black lines) and v5 (red lines), as a function of parameter and observation type.

\subsubsection{Data assimilation}

The variational data assimilation system in C-GLORSv5 has been slightly modified compared to its predecessor's reanalysis and in particular both observational and background-error covariances were retuned, plus a few additional improvements and bug fixes.

The tuning of in situ observational errors was achieved by using data assimilation output statistics from C-GLORSv4 and applying the posterior method of Desroziers et al. (2005). Such a method relies on the cross-covariance statistics of observation misfits and assimilation residuals to diagnose background- and observation-errors in observation space. It is broadly used in meteorological and oceanographic applications because of its simplicity, although limits of the methods are found in the case of incorrectly prescribed spatial correlations or asynchronous tuning of background- and observation-error variances (Menard, 2016).

Figure 1 shows the profiles of observational errors for in situ observations before and after the tuning, for the four in situ observation types assimilated in the system. While the shapes of the vertical profiles are very close in C-GLORSv4 and v5, salinity errors have been approximately halved in the upper ocean for all observation types, implying that salinity analysis increments in C-GLORSv4 were underestimated, based on this posterior diagnostics. Differences between the two temperature error profiles depend on the type, while mooring (buoys) errors are reduced, Argo and CTD (conductivity temperature depth) errors are increased and expandable bathythermograph (XBT) errors remain almost unchanged. The tuning in practice, flattens the differences in errors between the observation types, leading to a closer profile for the four observing networks than in C-GLORSv4. This result can be interpreted with the dominant effect of representativeness error compared to the instrumental error in ocean observations, the former being reasonably more similar between different observing networks.

Background-error vertical covariances have also been tuned in C-GLORSv5. The modification consisted in introducing a corrective coefficient, by means of which covariances were modulated in time and space. The new vertical EOFs operator $\mathbf{V}_{v}^{*}$ is formulated as

$\mathbf{V}_{v}^{*}=\alpha(t) \beta(\phi, \lambda) \mathbf{V}_{v}=\alpha(t) \beta(\phi, \lambda) \mathbf{U} \boldsymbol{\Lambda}^{1 / 2}$, 
where $\mathbf{V}_{v}$ is the uncorrected operator, as in C-GLORSv4, and $\alpha$ and $\beta$ are corrective coefficients, as a function of longitude and latitude, respectively, or time. The specification of both the coefficients was performed by applying the Desroziers method on the assimilation output statistics from C-GLORSv4, similarly to the tuning of the observational errors.

Figure 2 shows the new time-averaged background-error covariances after the application of the corrective coefficients for the temperature in the top $10 \mathrm{~m}$ of depth (top panel) and the difference with the corresponding standard deviations in C-GLORSv4 (bottom panel). The use of the corrective factor generally reduces the covariances at global scale, with a particularly large reduction in the tropical Pacific Ocean and within the North Pacific Gyre. As discussed in Storto et al. (2014, 2016a), the overestimation in the tropical Pacific Ocean was a known issue, attributable to the dataset from which EOFs are calculated, which is formed by monthly mean anomalies. Indeed, such an approach by construction confuses the ocean variability with the ocean error variance. These two were found to diverge especially in the tropical oceans, where errors were overestimated. Conversely, some regions dominated by strong mesoscale activity (Gulf Stream, Kuroshio, Antarctic Circumpolar Current) exhibit an increase in background-error variances, suggesting that the method of using monthly mean anomalies may underestimate error variances in these areas due to the coarse temporal resolution of the monthly anomalies with respect to the weekly assimilation frequency.

Figure 3 shows the temporal coefficient $\alpha$, which is assumed to be globally uniform. Even though its global definition cannot capture patterns associated with the geographical sampling of the observations, it mainly reproduces the change in the in situ observing system (Yang et al., 2016b), with a gradual background-error reduction during the deployment period of the Argo floats (2000s). Note also a temporary decrease in the inflation coefficient corresponding to the beginning of the altimetry missions (end of 1992), which might indicate the impact of the altimetric observing network on the reanalysis quality. The coefficient $\alpha$ should be considered as a preliminary attempt to introduce flow-dependent information in the background-error covariance characterization of C-GLORS. At the end of the reanalysis period, the background-error standard deviation is reduced by about $35 \%$ with respect to their nominal value at the beginning of the reanalysis.

C-GLORS implements a background quality check procedure that rejects observations whose square departure exceeds a certain number of times the sum of the observational and background-error variances. For the $i$ th observation, the observation retention criterion reads

$$
\left(y_{i}-H_{i}\left(x^{\mathrm{b}}\right)\right)^{2} \leq \gamma\left[\sigma_{\mathrm{o}, i}^{2}+\sigma_{\mathrm{b}, i}^{2}\right],
$$
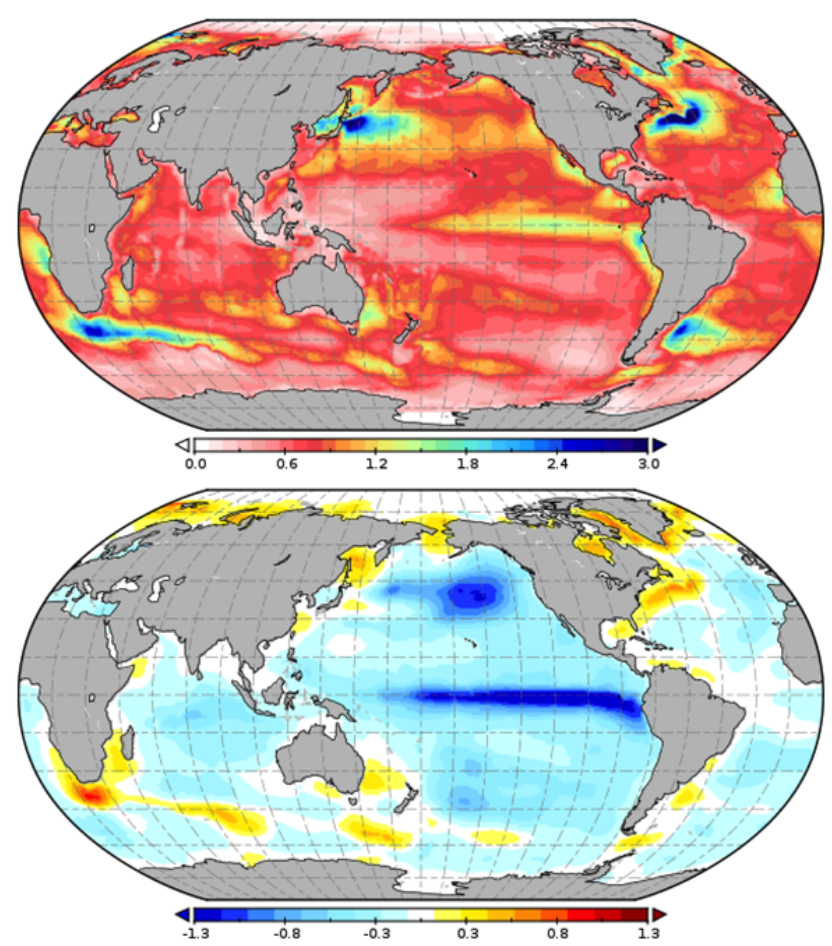

Figure 2. Season-averaged temperature background-error standard deviation in the top $10 \mathrm{~m}$ of depth in C-GLORSv5 (top panel), and difference with respect to the background errors used in CGLORSv4 (bottom panel).

with $\sigma_{\mathrm{o}, i}^{2}$ and $\sigma_{\mathrm{b}, i}^{2}$ the observation and background-error variances, in observation space, and $\gamma$ the quality check threshold. This scheme was also retuned, the threshold $\gamma$ being increased from 6 to 9 to allow a greater number of assimilated observations, particularly important in areas of strong mesoscale variability. More sophisticated non-linear quality control schemes have been recently implemented in OceanVar (Storto, 2016), and will be used in future releases of CGLORS.

The rejection of observations near the coast has also been softened, with a reduction in the minimum distance from 75 to $15 \mathrm{~km}$ from shorelines. Finally, a bug preventing the assimilation of observations located at a depth shallower than the middle of the first model level (around $0.5 \mathrm{~m}$ ) was fixed in C-GLORSv5, allowing a greater number of sea surface observations from in situ profiles to be ingested. This change produced a $0.9 \%$ increase in assimilated observations (peaking at about $3 \%$ at the beginning of the 1980 s when there were less profiles sampling the deep waters).

\subsubsection{Observational dataset}

As C-GLORSv5 is conceived to be continuously updated in delayed time mode, a change in the observational data was made during the production of the reanalysis. In particular, from 1979 to 2012 the in situ data were extracted 


\section{Background-error standard deviation inflation}

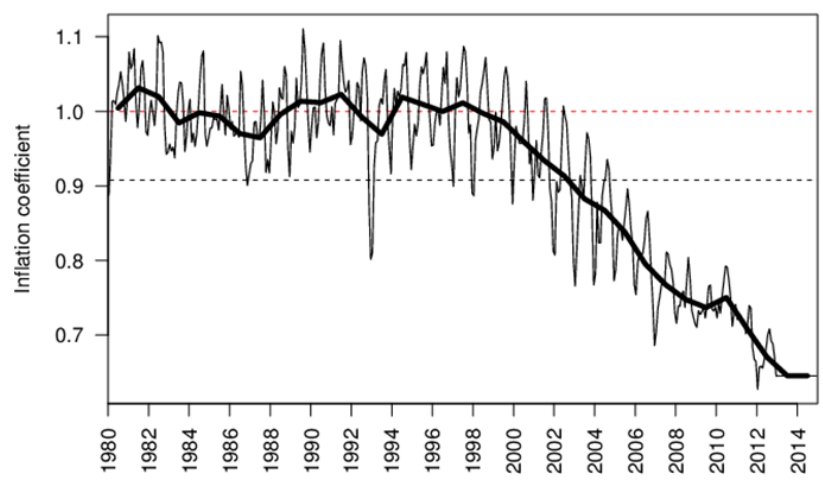

Figure 3. Background-error standard deviation temporal inflation (coefficient $\alpha(t)$ in Eq. 4). Thin lines refer to monthly means and thick lines to yearly means. Dashed black line corresponds to the long-term mean of $\alpha(t)$, while the dashed red line to the value of 1 , i.e. the reference value before the application of the inflation.

from EN3 (Ingleby and Huddleston, 2007). From 2013, the reanalysis assimilates hydrographic profiles from EN4 (Good et al., 2013). A similar change concerns also altimetry data: two versions of the delayed time along-track dataset from CLS/AVISO with the upgrade occurring at the beginning of 2013. The mean dynamic topography (MDT) in CGLORS is computed as long-term mean sea surface height (Storto e al., 2016a) from a twin experiment with the assimilation of in situ profiles only. Because the two versions of assimilated AVISO sea level anomalies (SLAs) are referenced to 1993-1999 and 1993-2012, respectively, at the beginning of 2013 the MDT was recalculated as 1993-2012 long-term mean from the previous 20 years of reanalysis and substituted to the 1993-1999 referenced MDT. This approach preserves the continuity of the MDT used and prevents from possible adjustments from 2013.

\subsubsection{Large-scale bias correction}

The large-scale bias correction (LSBC) scheme of C-GLORS relaxes the temperature and salinity towards large-scale univariate objective analyses of temperature and salinity measurements from hydrographic profiles. This scheme has proven successful for bias- and drift-correcting long-term diagnostics in C-GLORS, mostly arising from systematic errors in the forcing (Storto et al., 2016b). The new version of C-GLORS has a decreased temporal scale for use in this scheme, which changed from 3 to 36 months. Preliminary tests showed that a 3-month timescale was partly preventing the inter-annual variability of the heat content to evolve independently from the objective analyses, resulting in a too close reproduction of the latter. The new timescale shows robust in preventing large-scale biases without jeopardizing the reanalysis inter-annual variability. This is shown in Fig. 4, which reproduces the global ocean heat content in

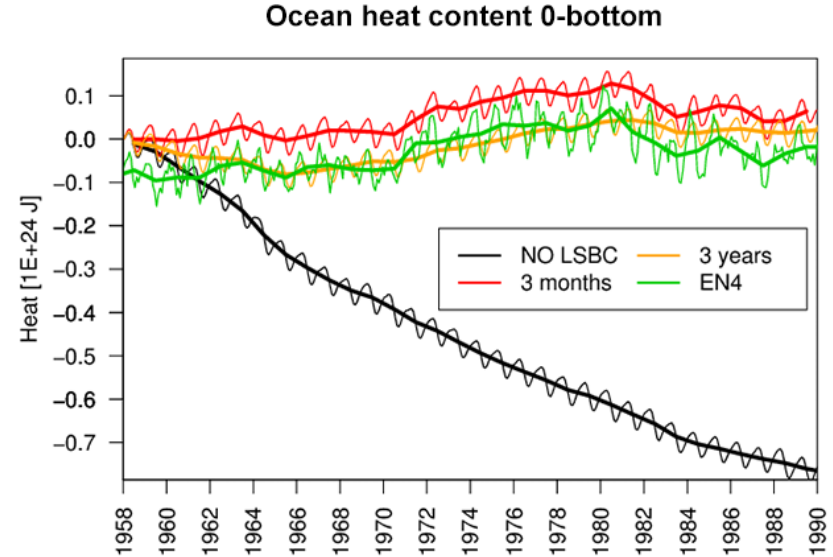

Figure 4. Total ocean heat content in a set of preliminary experiments during 1958-1990 performed to test the impact of the largescale bias correction (LSBC) timescale. Thin lines refer to monthly means and thick lines to yearly means. Black lines refer to the experiment without LSBC; red and orange lines to the experiment with LSBC and with a timescale of 3 months and 3 years, respectively. Also shown is the heat content computed from the UK Met Office EN4 dataset (Good et al., 2013).

non-assimilative experiments covering the period 1958-1989 for different timescales of the large-scale bias correction. Without LSBC, the model drifts away from the initial conditions, due to weakly negative air-sea heat fluxes (Storto et al., 2016b). With a 3-month period, the variability of the modelled ocean heat content resamples very well that of EN4, while the 3-year timescale prevents the simulation to drift without following closely EN4.

\subsubsection{Sea-ice data assimilation}

In C-GLORSv4, we assimilated sea-ice concentration analyses retrieved from the Defense Meteorological Satellite Program (DMSP) constellation of passive microwave radiometers, provided by the National Snow and Ice Data Center (NSIDC) through the use of the NASA team algorithm (Cavalieri et al., 1999). While C-GLORSv4 has a good representation of seasonal and inter-annual variations in sea-ice extent and area, the ice volume was characterized by anomalous variability, which we found was caused by the assimilation of sea-ice concentration in highly ice-covered areas, leading to spurious increases in ice thickness. This is a common problem when sea-ice concentration is assimilated but no constraint is applied to sea-ice thickness (e.g. Tietsche et al., 2013). In C-GLORSv5 we introduce a nudging scheme in order to weakly constrain sea-ice thickness in the Arctic Ocean. Model sea-ice thickness is relaxed towards PIOMAS data (Pan-Arctic Ice Ocean Modeling and Assimilation System; Zhang and Rothrock, 2003) with a 15-day relaxation timescale. Although PIOMAS is a reanalysis itself that assimilates only ice concentration data, it has been extensively 

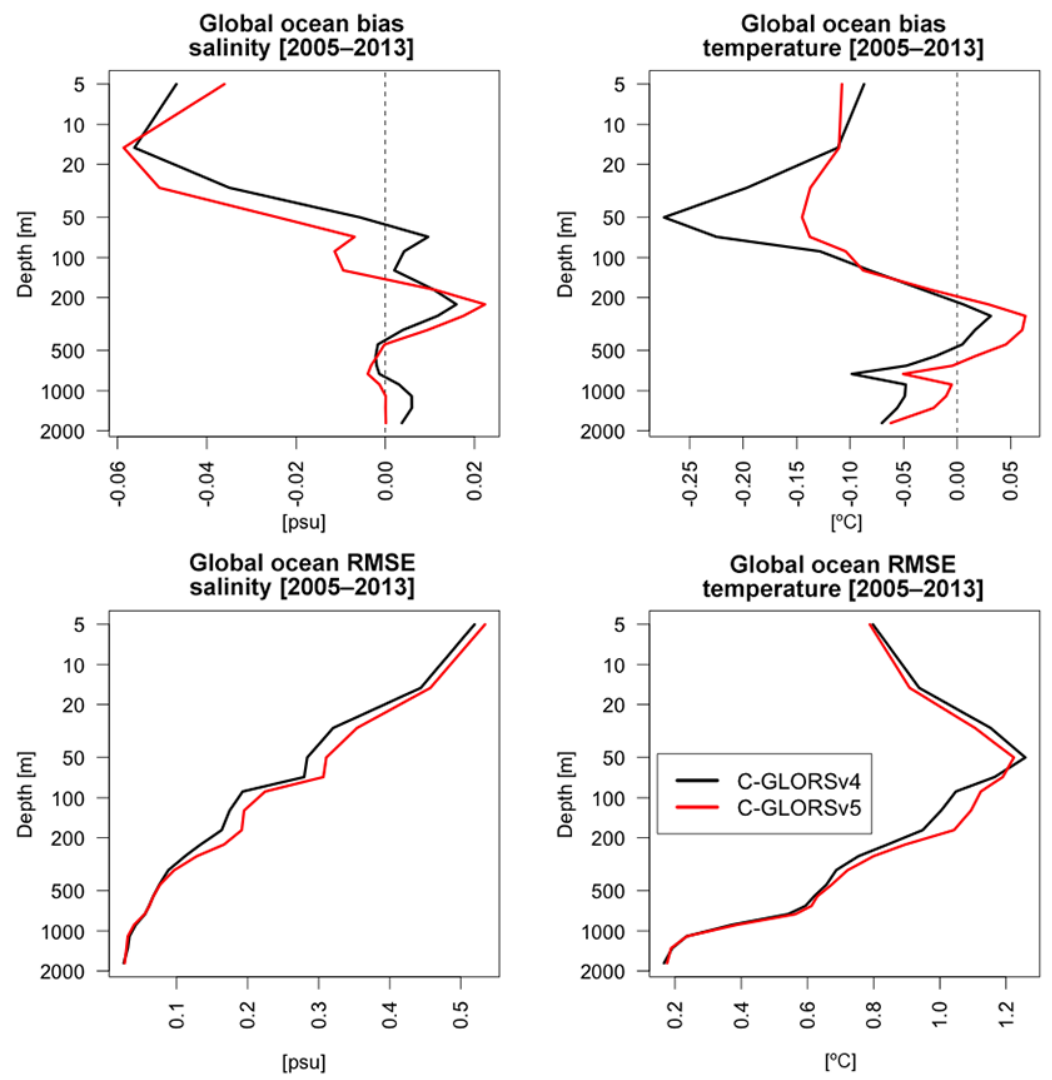

Figure 5. Verification skill scores (bias and RMSE) of C-GLORSv4 and C-GLORSv5 against Argo floats from EN4 over the period 20052013 as a function of ocean depth. Units are psu and degrees Celsius for salinity and temperature, respectively. Bias is defined as observation minus model fields.

validated against independent data and proves a reliable tool for the reconstruction of the Arctic sea-ice volume in the past few decades (Schweiger et al., 2011). This approach proves able to mitigate the spurious variability of sea-ice volume, although future work should be done to implement robust multivariate corrections of sea-ice parameters in polar regions.

\subsubsection{Initialization}

The initialization strategy in C-CGLORSv5 was changed. While C-GLORSv4 was initialized through a spin-up with repeated atmospheric forcing relative to 1978 for 10 years, C-GLORSv5 was initialized using the 1979-1982 mean January conditions. This led to a weaker shock at the beginning of the reanalysis, allowing the dissemination of the reanalysis data from 1980.

\section{Selected results}

In this section, we review the results that summarize the main improvements of C-GLORSv5 compared to its predecessor (C-GLORSv4).

\subsection{Verification skill scores}

Verification of model fields against Argo floats from EN4 was conducted for both C-GLORSv4 and C-GLORSv5. Output fields are compared to the data before the assimilation. Observations from floats represent a fairly independent dataset, because their successive measurements are sampled at different locations, thus the temporal correlation of the observational error can be reasonably assumed to be negligible. We report in Fig. 5, global vertical profiles of bias and root mean square error (RMSE) for salinity and temperature. The validation results suggest that differences between the two versions are not large. In particular, C-GLORSv5 is able to reduce the warm temperature bias in the upper ocean, which leads to a corresponding RMSE decrease in the top $80 \mathrm{~m}$ of depth. Below this depth, statistics show a cold bias and a corresponding slight increase in RMSE, suggesting the need to further retune the vertical mixing scheme. On the other hand, salinity skill scores are characterized by a saline bias in the upper part of the ocean, which slightly increase in C-GLORSv5, and it is due to the detrimental contribution of the high latitudes (Fig. S1 in the Supplement shows the skill scores for the global ocean between $60^{\circ} \mathrm{S}$ and $60^{\circ} \mathrm{N}$, 

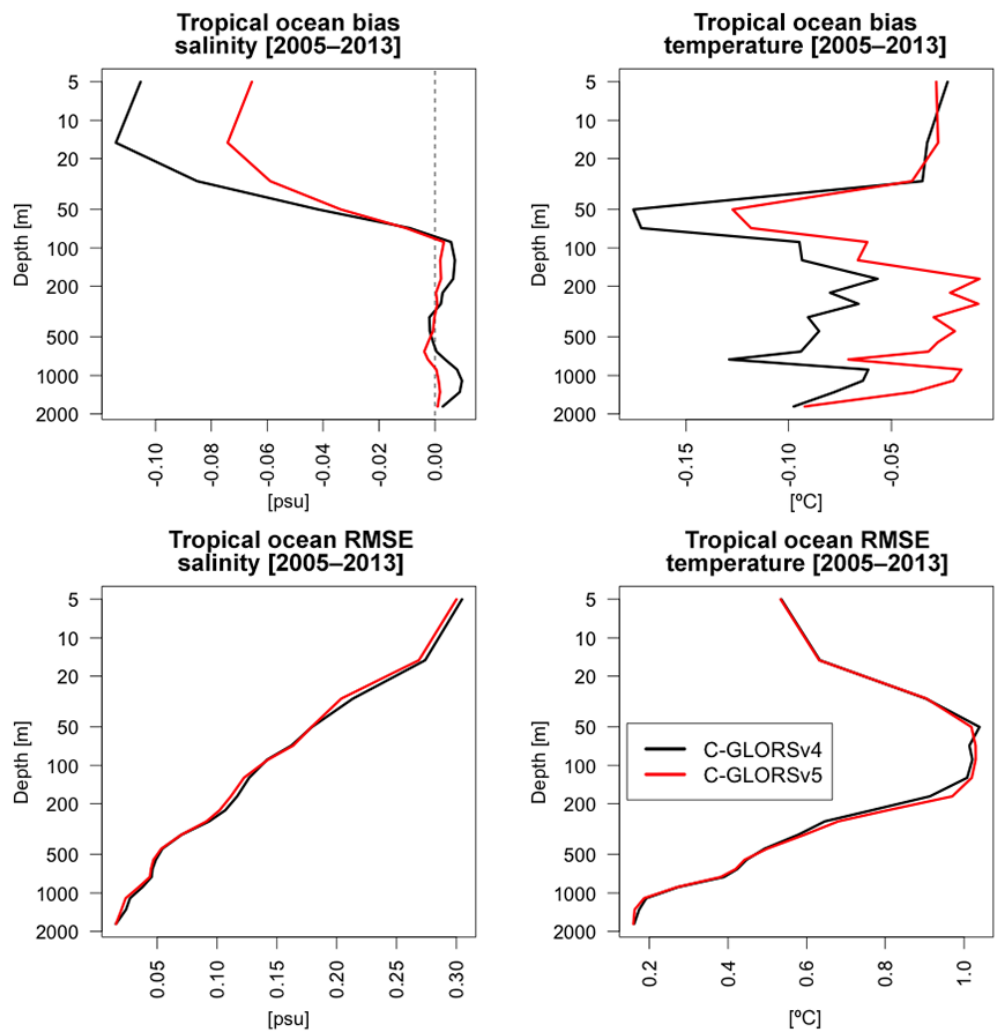

Figure 6. As Fig. 5, but for the tropical ocean skill scores (between $30^{\circ} \mathrm{S}$ and $30^{\circ} \mathrm{N}$ ).

the salinity of v5 exhibiting a smaller RMSE than v4), characterized by an enhanced saline bias.

The improvement of the upper ocean temperature is particularly evident in the tropical region. Figure 6 reproduces the same statistics as Fig. 5 but for the tropical oceans only, highlighting the significant reduction of bias for salinity in the top $50 \mathrm{~m}$ and the temperature below $50 \mathrm{~m}$, although RMSE skill scores are not significantly affected. In the North Atlantic Ocean (Fig. 7), results show the improvement of salinity scores, again in the first $50 \mathrm{~m}$, while the impact of the version upgrade is positive at depths around the mixed layer depth (40 to $50 \mathrm{~m}$ of depth) and negative below, up to $800 \mathrm{~m}$ of depth.

Figure 8 shows the sea surface temperature RMSE difference between C-GLORSv4 and v5 against NOAA sea surface temperature (SST) $1 / 4^{\circ}$ analyses (Reynolds et al., 2007). Although differences are not large, e.g. compared to the validation dataset accuracy (about $0.6 \mathrm{~K}$ ), C-GLORSv5 improves the representation of the SST especially at low latitudes and in particular in the Pacific Ocean. The latest version appears however less skilful around the Gulf Stream and the Kuroshio Extension. As v5 skill scores from the in situ network do not seem worse than $\mathrm{v} 4$ in the North Atlantic near-surface ocean temperature (Fig. 7), we conclude that this worsening is due to the increase in background-error standard deviation in this area - i.e. heavier weight given to in situ observations - and possible inconsistency between the in situ and the satellite SST observations.

A slight worsening occurs also at very high latitudes, although in these areas NOAA SST data are mostly inferred from sea-ice concentration data through empirical relationships (Reynolds et al., 2007) and therefore are less reliable for validation purposes. The global improvement of SST in terms of RMSE decrease is $3.2 \%$. It peaks at $7.7 \%$ in the tropics (from $30^{\circ} \mathrm{S}$ to $30^{\circ} \mathrm{N}$ ), where the C-GLORSv4 warm bias is reduced in C-GLORSv5.

\subsection{Global ocean heat content and steric sea level rise}

Among the main climate change signatures on the oceans, the ocean heat content has increased notably during the last few decades (Levitus et al., 2012). Related to it, the change in the global steric sea level represents a fundamental diagnostics that ocean reanalyses need to capture, whereas the global change in the halosteric component is rather neutral at global scale (Stammer et al., 2013). Figure 9 shows the global steric sea level change (calculated over the top $2000 \mathrm{~m}$, for consistency with observational datasets) in C-GLORSv4, CGLORSv5, the NODC in situ based estimates (Levitus et al., 2012), and the dataset proposed by Storto et al. (2016c) for the period 2003-2011 merging satellite altimetry and gravimetry data. For the latter, global steric sea level is in- 

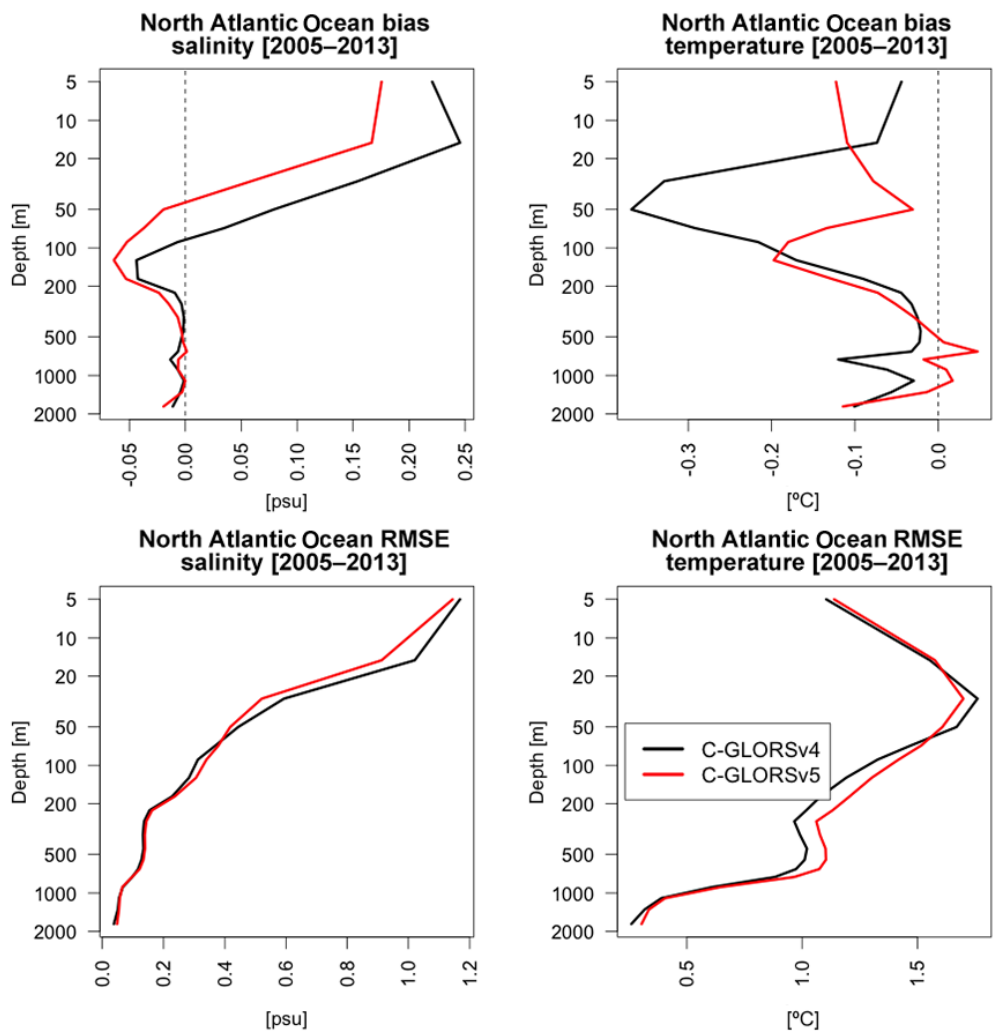

Figure 7. As Fig. 5, but for the North Atlantic Ocean skill scores (between $20^{\circ} \mathrm{S}$ and $60^{\circ} \mathrm{N}$ and between 80 and $10^{\circ} \mathrm{W}$ ).

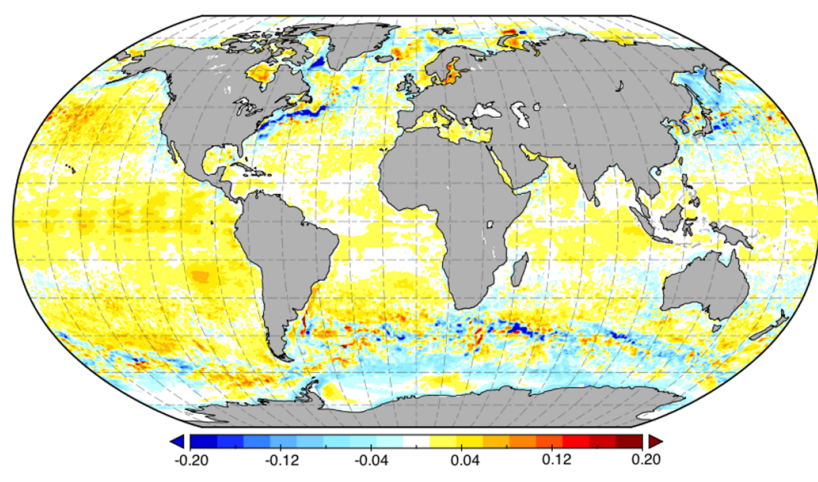

Figure 8. Map of differences of SST Root Mean Square error between C-GLORSv4 and C-GLORSv5. The RMSE is computed against NOAA SST $1 / 4$ daily analyses (Reynolds et al., 2007). Positive (negative) differences indicate that C-GLORSv5 outperforms (underperforms) C-GLORSv4. Units are degrees Celsius.

ferred by the difference of global sea level change from altimetric missions minus global barystatic sea level change from the GRACE gravimetric mission. C-GLORv5 data start in 1980 unlike C-GLORSv4 in 1982. The 1980-1982 years are characterized by an abrupt steric sea level decrease following the eruption of El Chichón (Church et al., 2005). Similarly, a decrease at the beginning of the 1990s follows the
Pinatubo eruption, whose effects appear to last longer in CGLORSv5. A significant difference between the two versions of C-GLORS occurs in the last decade (from 2005 onwards), where C-GLORSv5 reduces the warming hiatus (Trenberth and Fasullo, 2013) present in C-GLORSv4. This feature leads C-GLORSv5 to have a 2003-2011 trend higher than C-GLORSv4 (0.57 vs. $0.02 \mathrm{~mm}$ year $^{-1}$ ) and much closer to the satellite independent estimates $\left(0.77 \mathrm{~mm}\right.$ year $\left.^{-1}\right)$, with also a significant increase in temporal correlation ( 0.86 vs. 0.54 ) with respect to the satellite-derived dataset. Trends and correlations for the entire common period (1983-2013) are in close agreement between the two versions and with the NODC data, showing a high correlation (0.93 and 0.94) and comparable linear trends $\left(0.64\right.$ and $0.65 \mathrm{~mm}$ year $^{-1}$, against $0.75 \mathrm{~mm}$ year $^{-1}$ for NODC) for $\mathrm{v} 4$ and $\mathrm{v} 5$, respectively.

To further deepen the main changes of C-GLORSv5 with respect to $\mathrm{v} 4$ in terms of the last decade's heat content increase, Fig. 10 shows the 2005-2013 top $2000 \mathrm{~m}$ heat content trend in C-GLORSv5, the NOAA/NODC datasets and trend differences between C-GLORSv5 and v4. From this sketch, it appears that heat content trend is in close agreement with the NOAA/NODC estimates. In particular, the increase in linear trends in C-GLORSv5 with respect to its predecessor occurs mostly in the middle of the North Atlantic Gyre and, only partly, in the tropical Pacific Ocean. The heat content difference in the second half of the 2000s 


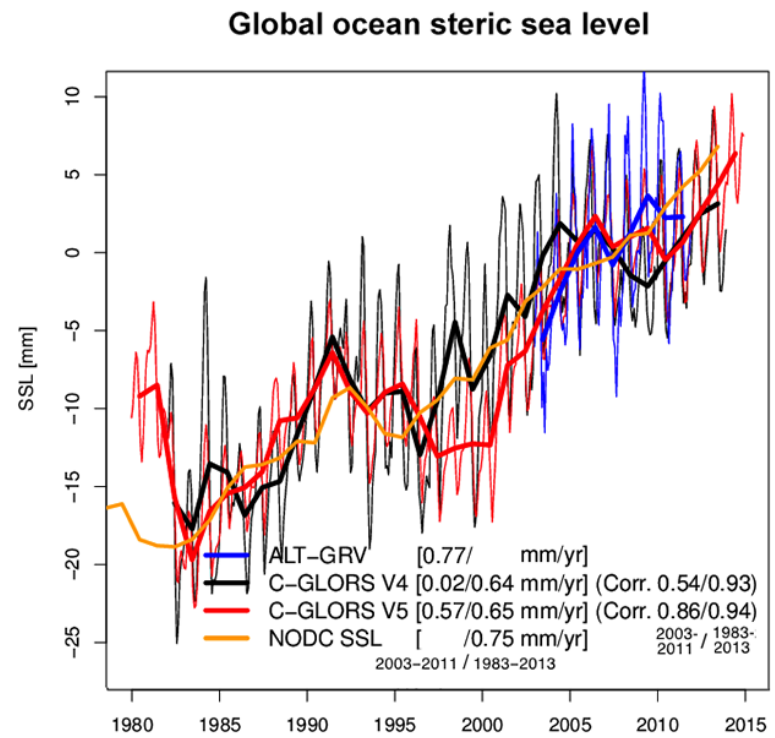

Figure 9. Global ocean steric sea level (SSL) (calculated over the top $2000 \mathrm{~m}$ ) for the reanalyses C-GLORSv4 and v5, along with estimates from satellite altimetry and gravimetry (ALT-GRV, Storto et al., 2016c) and NODC pentadal estimates (Levitus et al., 2012). The legend reports linear trends for the period 2003-2011 (for comparison with ALT-GRV), and 1983-2013 (for comparison with NODC SSL and the temporal correlation against the two validating datasets during their respective period. Correlations are statistically significant if greater than 0.25 and 0.46 at $99 \%$ confidence level, based on bootstrapping, for the 2003-2011 monthly data and the 1983-2013 yearly data validation, respectively.

between the two reanalysis versions is mostly contributed by the North Atlantic Ocean, whose trends now closely resembles those estimated by the NOAA/NODC. This is in agreement with the SST RMSE reduction in the middle of the North Atlantic Gyre, previously shown, which contributes to drive the subsurface inter-annual variability shown here in terms of trends. This improvement is likely due to the weakening of the bias correction scheme in association with the decrease in background-error covariances in the last decade (Fig. 3), which jointly strengthen the weight given to temperature measurements from 2000 onwards and sustain the global signal.

\subsection{Atlantic meridional overturning circulation and associated heat transport}

We compare, in this section, the representation of the Atlantic Ocean meridional overturning circulation (AMOC) estimated from C-GLORSv4 and v5 with the RAPID-MOC array estimates (Rayner et al., 2011). This is shown in the top panel of Fig. 11 in terms of the maximum of the meridional streamfunction at $26^{\circ} \mathrm{N}$. During the period of availability of the RAPID array data (2004-2013), C-GLORSv5 has a slightly better correlation with the observational estimates

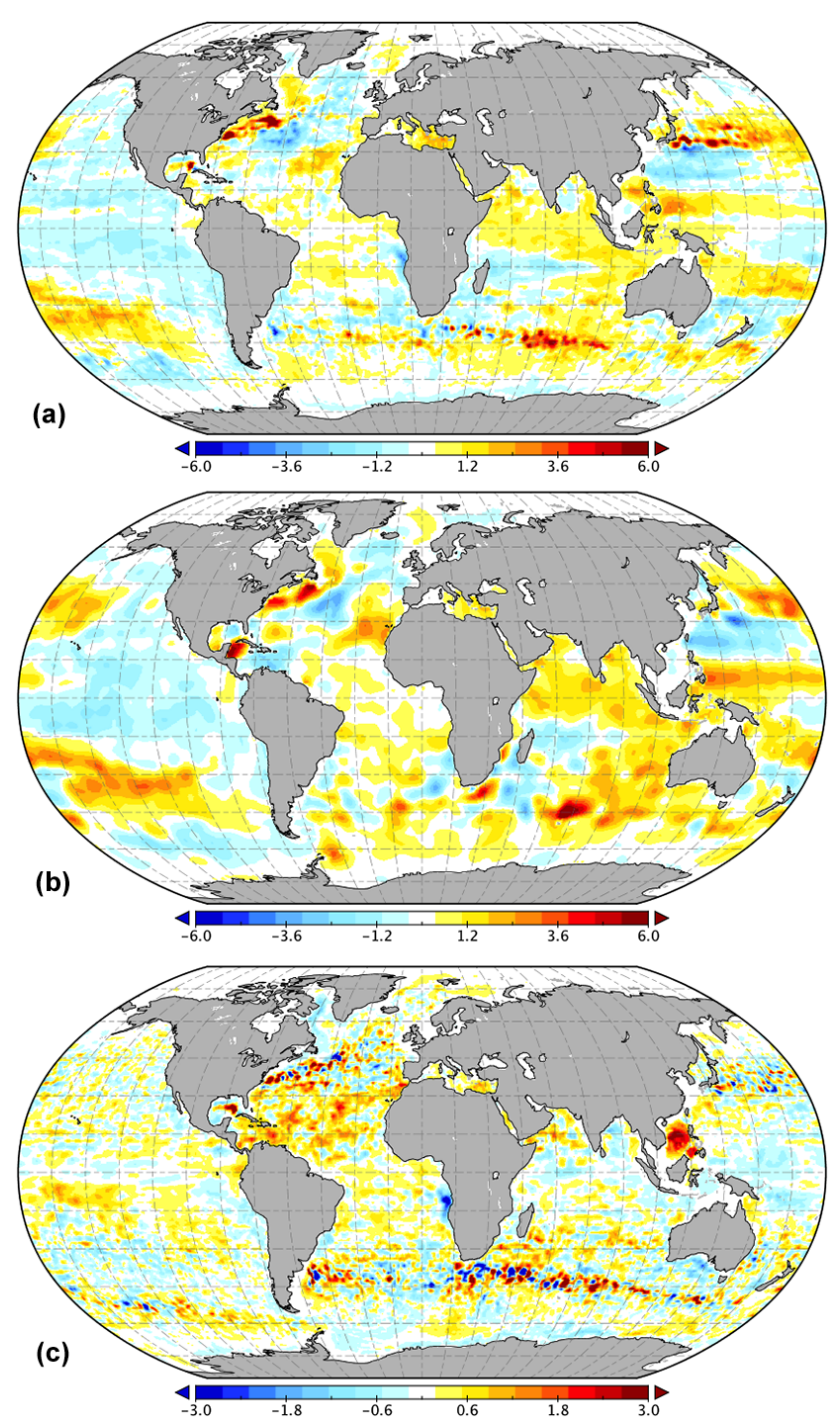

Figure 10. (a) Top $2000 \mathrm{~m}$ heat content linear trend over the period 2005-2013 in C-GLORSv5, (b) NOAA/NODC data from Levitus et al. (2012), and (c) difference between C-GLORSv5 and CGLORSv4. Units are $1 \times 10^{+18} \mathrm{~J}_{\text {year }}{ }^{-1}$.

with respect to C-GLORSv5 ( 0.83 vs. 0.80 for the monthly means and 0.87 vs. 0.82 for the yearly means).

More importantly, the long-term average of C-GLORSv5 is $1.3 \mathrm{~Sv}$ higher than in C-GLORSv4, getting closer to the observational estimates and reducing the underestimation of AMOC in the previous reanalysis, due to an underestimation of the Florida Current and the interior southward transports (Storto et al., 2016a). In particular, the largest effect of the new reanalysis configuration involves the strengthening of the southward transport of the upper North Atlantic Deep Water at $26^{\circ} \mathrm{N}$ (NADW; defined according to McCarthy et al., 2015), which increases from -14.6 to $-16.0 \mathrm{~Sv}$. Qualitatively similar results apply to the non-Ekman component of the overturning streamfunction (Fig. 11, middle panel), 

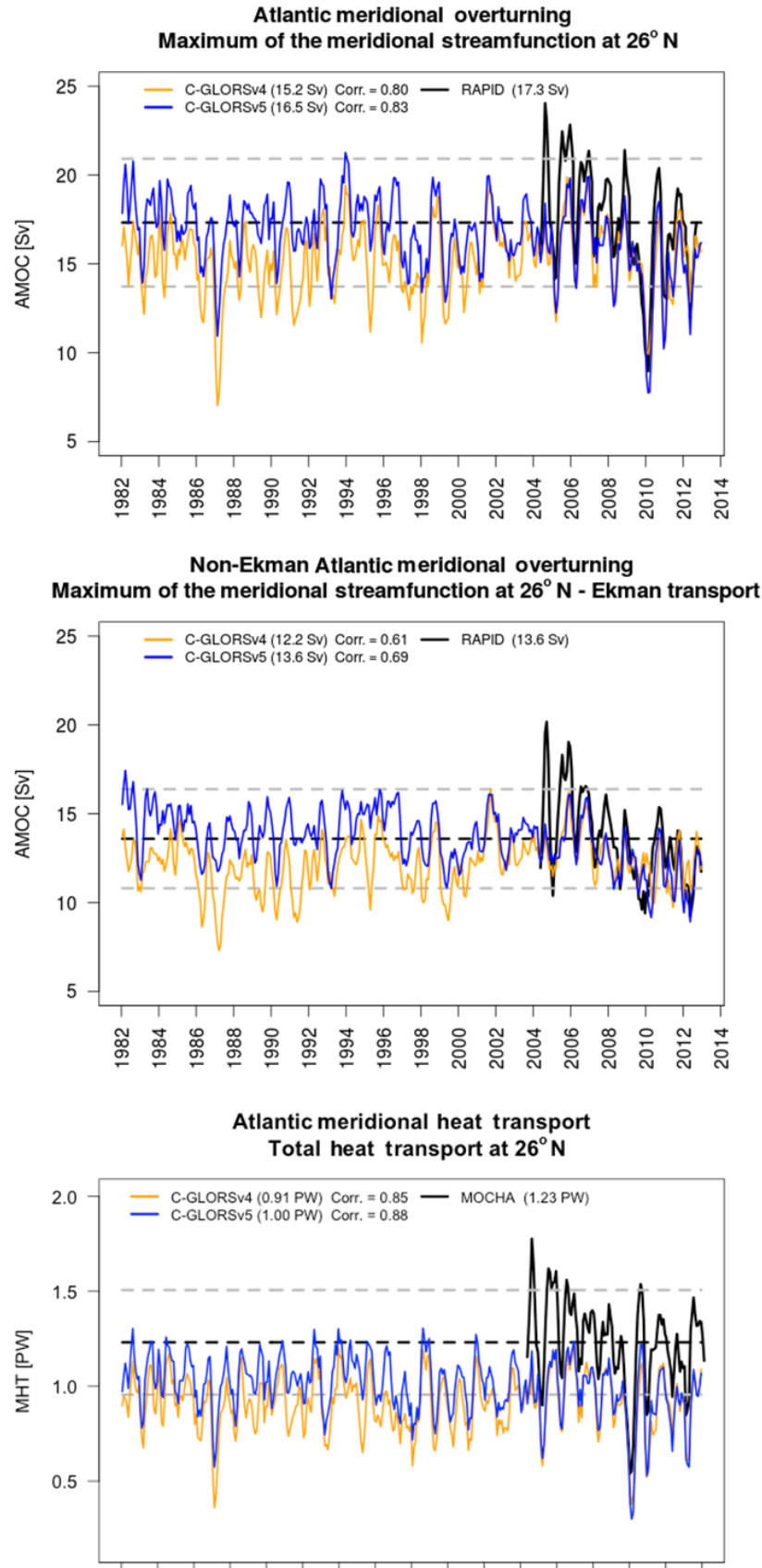

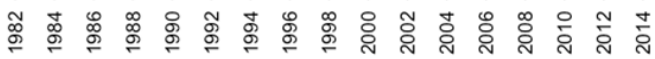

Figure 11. Atlantic meridional overturning (AMOC, top panel, defined as maximum of the meridional streamfunction at $\left.26.5^{\circ} \mathrm{N}\right)$, non-Ekman component of the meridional streamfunction (AMOC minus Ekman transport, middle panel) and heat transport (MHT, bottom panel) for C-GLORSv4, C-GLORSv5 and the RAPIDMOCHA array. Units are $\mathrm{Sv}\left(1 \mathrm{~Sv}=1 \times 10^{+6} \mathrm{~m}^{3} \mathrm{~s}^{-1}\right)$ and PW ( $1 \mathrm{PW}=1 \times 10^{+15}$ Watts) for the overturning streamfunction and the heat transport, respectively. The plots also show (in dashed lines) the RAPID-MOCHA mean values (black lines) \pm 1 standard deviation (grey lines). which represents a better proxy of the ability of the reanalysis in reproducing the density driven circulation (e.g. Roberts et al., 2013). Although the correlation with respect to the RAPID-MOC estimates are slightly smaller, C-GLORSv5 exhibits a significantly larger correlation than C-GLORSv4 (0.69 vs. 0.61$)$ and the same time mean value as RAPID $(13.6 \mathrm{~Sv})$.

The increase of AMOC in C-GLORSv5 is more evident up to the beginning of the 2000s; afterwards, the two versions show very similar values, i.e. the mean increase of AMOC is significant in data-poor periods, suggesting that it is likely due to refinement of large-scale bias correction, atmospheric forcing, model vertical physics or sea-ice treatment rather than the tuning of the 3DVAR scheme. However, the reanalyses fail in capturing the first two AMOC peaks (2005 and 2006), due to the underestimation of the Florida Strait contribution to the total AMOC (Fig. S2), likely caused by the lack of in situ observations at that time along with the difficulty in resolving the Florida Strait geometry with the $1 / 4^{\circ}$ model resolution.

The meridional heat transport (MHT) at $26^{\circ} \mathrm{N}$ appears slightly larger in C-GLORSv5 (1.0 vs. 0.9 PW) compared to C-GLORSv4, closer to the mean value derived from the RAPID-MOCHA heat flux array (1.23 PW, Johns et al., 2011). The bottom panel of Fig. 11 reproduces the time series of MHT for the period 1982-2013. Note, however, that the underestimation of the heat transport in the reanalysis compared to RAPID estimates might arise from the geostrophic approximations implicit in the RAPID calculations (Stepanov et al., 2016).

\subsection{Sea-ice reconstruction}

Sea-ice areas and volumes from C-GLORSv5 are shown in Fig. 12 for both the Antarctic and Arctic oceans and compared to C-GLORSv4. Sea-ice areas between version 4 and 5 are in close agreement for both polar regions, as a consequence of the same sea-ice concentration data assimilation scheme and observational dataset. On the contrary, the seaice volume variability and trend significantly change between the two versions, especially in the Arctic region.

For the latter, the spurious variability present in version 4 - sea-ice volume minima during 1987-1988 and maximum during 2006 - is replaced by a more realistic and smaller inter-annual variability, with minima correctly occurring during September 2007 and 2012. Furthermore, the sea-ice accumulation in the Beaufort Gyre that affected C-GLORSv4 (not shown) is no longer present in v5. This obviously improves the estimates of the autumn (October-November) sea-ice volume trends, equal to $-1190(-295) \mathrm{km}^{3}$ year $^{-1}$ for the 1980-2014 (2004-2008) period, opposed to CGLORSv4 that shows $-4025(-114) \mathrm{km}^{3}$ year $^{-1}$, in close agreement with estimates from PIOMAS for the entire period $\left(-280 \mathrm{~km}^{3}\right.$ year $\left.^{-1}\right)$ or from ICESat for the 2004-2008 period $\left(-1240 \mathrm{~km}^{3}\right.$ year-1). The weak constraint on the sea- 


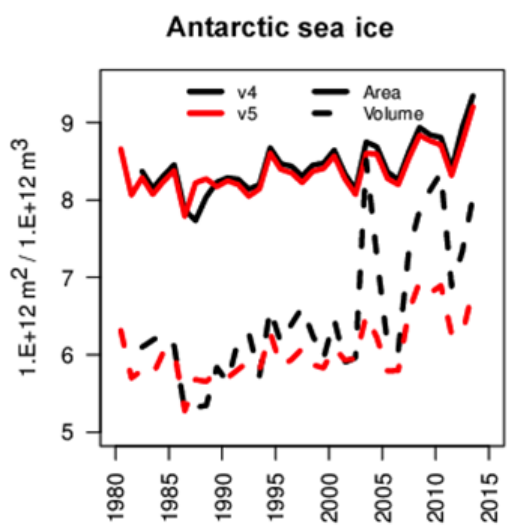

Antarctic sea ice

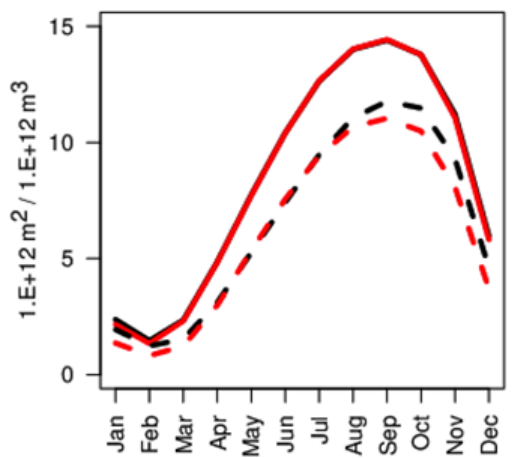

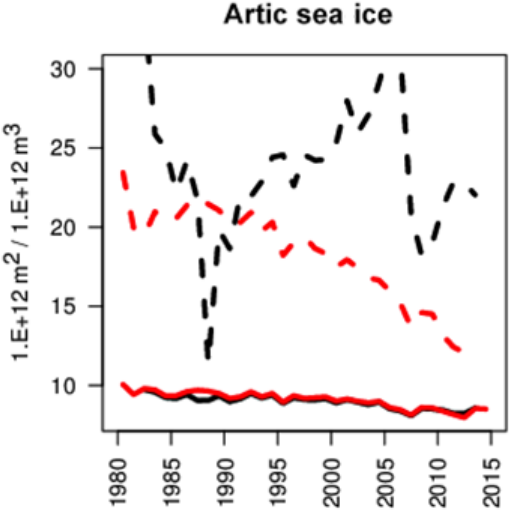

Artic sea ice

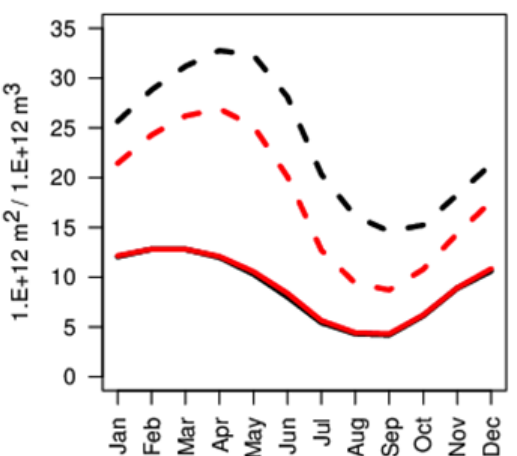

Figure 12. Antarctic (left panels) and Arctic (right panels) sea-ice area (solid lines) and volume (dashed lines) from C-GLORSv4 and v5. Top panels show yearly mean values and bottom panels show the 1982-2013 monthly climatology.

ice thickness thus proves robust to fix the spurious variability problems and provides sea-ice volume estimates in agreement with observation-based products.

Similarly, sea-ice volume spurious variability, albeit smaller, is recovered in the Antarctic region as well. This leads to better sea-ice volume trend estimates, equal to $+34 \mathrm{~km}^{3}$ year $^{-1}$ for the entire period and $-250 \mathrm{~km}^{3}$ year $^{-1}$ for the spring periods in 2003-2008, in closer agreement to other data assimilative experiments $\left(+36 \mathrm{~km}^{3}\right.$ year $^{-1}$ during 1980-2008, Massonet et al., 2013) and ICESat derived estimates $\left(-266 \mathrm{~km}^{3}\right.$ year $^{-1}$ across $2003-2008$ springs, Kurtz and Markus, 2012) with respect to C-GLORSv4 (+77 and $-698 \mathrm{~km}^{3}$ year $^{-1}$, respectively), where an overestimation of trends in both periods occurred. It should be noted that here no sea-ice thickness constraint is applied because of lack of thickness data in the Antarctic region, suggesting that the retuning of the data assimilation system and the use of uncorrected atmospheric forcing may be responsible for the improved sea-ice variability in the polar regions.

Based on this assessment, C-GLORSv5 may be used as a tool for investigating the ocean and sea-ice inter-annual variability in polar regions. For instance, Mayer et al. (2016) make extensive use of C-GLORSv5 data (ocean heat con- tent, sea-ice concentration and thickness, sea-ice velocities) to investigate the Arctic region energy imbalance.

\subsection{Air-sea heat flux}

A possible application of ocean reanalyses is the study of heat budget (e.g. Yang et al., 2016a). Therefore, validation of air-sea heat fluxes represents a necessary step for this kind of application. C-GLORSv4 was affected by an underestimation of air-sea net heat flux (Valdivieso et al., 2016) due, among other factors, to the radiative flux corrections that were unbalanced with turbulent atmospheric forcing, inducing spuriously negative net heat fluxes at low- and midlatitudes (Storto et al., 2016a).

The use of uncorrected forcing along with the tuning of the data assimilation system leads to reduced surface biases in C-GLORSv5, which translates to better air-sea heat fluxes. This feature is shown in Fig. 13, in terms of zonally averaged monthly climatology of net heat flux from C-GLORSv5, and differences between C-GLORSv4 and OAFlux (objectively analysed air-sea fluxes; Yu and Weller, 2007), and CGLORSv5 and OAFlux. OAFlux is a satellite-based air-sea flux dataset that relies on the ISCCP (International Satellite Cloud Climatology Project, Zhang et al., 2007) for the net radiative fluxes at the sea surface. Despite the large uncer- 

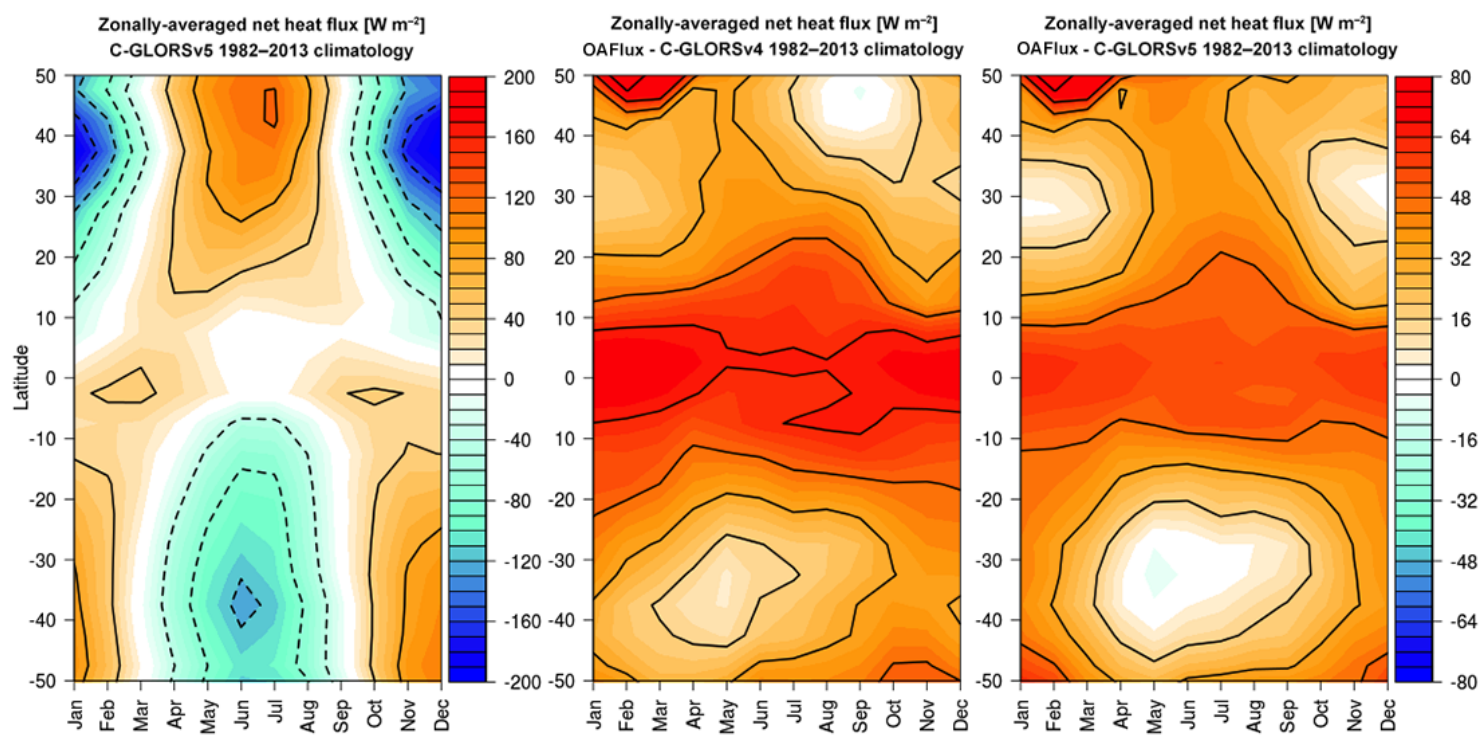

Figure 13. Zonally averaged net heat flux (downwards) climatology (1982-2013): C-GLORSv5 (left panel), difference between OAFlux and C-GLORSv4 (middle panel) and difference between OAFlux and C-GLORSv5 (right panel).

tainty of net heat flux from observational estimates and reanalyses (Valdivieso et al., 2016), the use of this independent dataset for the reanalysis validation suggests that CGLORSv5 has the net heat flux in the tropics (year-round) in closer agreement to OAFlux with respect to C-GLORSv4. Boreal winter fluxes in the Southern Ocean, underestimated in C-GLORSv4, also appear now in close agreement.

Improved heat flux estimates emerge also in the global net heat flux average. While the previous C-GLORS reanalysis system was characterized by a large negative imbalance (Valdivieso et al., 2016) equal to $-11.2 \mathrm{~W} \mathrm{~m}^{-2}$, C-GLORS exhibits a much smaller imbalance of $-3.9 \mathrm{~W} \mathrm{~m}^{-2}$. Turbulent (latent and sensible) heat fluxes are in practice unchanged between the two versions, the differences of which arise from the radiative fluxes, gaining, in particular, $2.7 \mathrm{~W} \mathrm{~m}^{-2}$ from the net long-wave flux, and $4.9 \mathrm{~W} \mathrm{~m}^{-2}$ from the net shortwave flux. Both increases can be ascribed to the turning off of the radiative forcing correction; for the long-wave flux increase, the reduction in the warm tropical bias also plays a role.

\section{Summary and conclusions}

We describe in this article the C-GLORSv5 global ocean reanalyses dataset, available from http://www. pangaea.de (https://dx.doi.org/10.1594/PANGAEA.857995). The dataset covers the 1980-2014 period and is being updated in delayed time (with approximately 1-year delay, due to the delayed time reprocessing of all input observational datasets). As a global ocean product, C-GLORSv5 may be useful for a large variety of applications that range from climate monitoring to ocean- and process-related studies, to downstream applications (biogeochemistry, fisheries, sediment, dispersion, etc.) and regional downscaling, to initialization of long-range prediction systems, etc.

Following the lessons learned during the validation exercise of the previous version, this version of C-GLORS contains a number of significant improvements, among which a complete retuning of the data assimilation system (especially background- and observation-errors), retuned schemes for the large-scale bias correction and sea-ice data assimilation, as well as an updated version of input datasets and an improved initialization strategy. Additionally, a backgrounderror temporal inflation coefficient has been introduced to mimic the reanalysis accuracy increase corresponding to the Argo floats deployment. The C-GLORSv5 reanalysis system also produced daily mean outputs available on demand, further to standard monthly mean outputs detailed in Appendix A.

While it is difficult to disentangle the individual effect of the reanalysis upgrades on the resulting reanalysis accuracy, we have focussed the validation exercise presented in Sect. 3 on highlighting the main changes and improvements of CGLORSv5 with respect to its predecessor C-GLORSv4. Validation skill scores appear comparable between the two products, although C-GLORSv5 presents an improved representation of the upper ocean (top $80 \mathrm{~m}$ ) temperature mean state and variability, particularly evident in the tropical region with a reduction of upper ocean warm biases, which in turn leads to an improved representation of the air-sea heat fluxes. For some skill scores, such as salinity in the upper ocean of polar regions and temperature below $100 \mathrm{~m}$ of depth, the changes in version 5 appears however slightly detrimental, requiring a further tuning of the model parameterizations (e.g. vertical 
mixing). Skill scores of SST against satellite data are also improved at global scale, although spots of increased RMSE exist, corresponding to areas of large variability, most likely due to the retuning of background-error covariances and the heavier weight attributed to in situ profiles.

The heat content change in the last decade also appears in closer agreement with independent estimates, likely due to the combined effect of the improved surface state and retuning of assimilation and bias-correction components of C-GLORSv5. This feature emerges in the North Atlantic Ocean. As a consequence, the representation of the Atlantic Ocean overturning circulation is also concerned with CGLORSv5 showing a strengthening that brings it closer to the RAPID array estimates.

As no constraint was applied to sea-ice thickness in CGLORSv4, the absence of sea-ice conservation methods - as the ones proposed, for instance, by Tietsche et al. (2013) caused drifts in the sea-ice volume time series. An intermediate solution consisting in a weakly relaxation towards realistic sea-ice thickness data was implemented in C-GLORS for the Arctic region, which led to inter-annual variability for sea-ice volume in accordance to many model and observational studies. In future releases of C-GLORS, multivariate sea-ice assimilation will be considered, as it emerges as the desired strategy to simultaneously correct sea-ice parameters from sea-ice concentration data with multivariate balances, without the recourse to empirical nudging schemes for the surface state assimilation.

Overall, the reanalysis proves a valuable tool not only for regional downscaling and downstreaming applications, but also for process- and budget-oriented studies concerning, for instance, heat exchanges, air-sea fluxes and sea-ice energy. Additionally, climate-oriented ocean simulations (e.g. the ocean components of the Coupled Model Intercomparison Project, CMIP; e.g. Taylor et al., 2012; Griffies et al., 2016), may benefit from this dataset for comparison and validation purposes.

\section{Data availability}

The according information can be found in Appendix A. 


\section{Appendix A: Product description}

The following table describes the ocean and seaice parameters available from C-GLORSv5 at doi:10.1594/PANGAEA.857995 (Storto and Masina, 2016, https://doi.pangaea.de/10.1594/PANGAEA.857995). All variables are available as monthly means over the period 1980-2014 in NetCDF format. Two-dimensional variables are

Table A1. C-GLORSv5 disseminated ocean and sea-ice parameters. interpolated onto a global regular grid at $1 / 2^{\circ}$ horizontal resolution. Three-dimensional variables (temperature, salinity and currents) are freely available via FTP (File Transfer Protocol) upon registration at http://www.cmcc.it/c-glors. Due to their large size, high-frequency variables (daily means) are available on demand by request at http://www.cmcc.it/ c-glors/index.php?sec $=8$ or by contacting the authors.

\begin{tabular}{|c|c|c|}
\hline \multicolumn{3}{|l|}{ Two-dimensional variables } \\
\hline Variable name & Full name/meaning & Units \\
\hline barotropic_streamfunction & Barotropic streamfunction & $\mathrm{m}^{3} \mathrm{~s}^{-1}$ \\
\hline freshwater_content_0-300 & Freshwater content in the top $300 \mathrm{~m}$ & $\mathrm{~m}$ \\
\hline freshwater_content_0-700 & Freshwater content in the top $700 \mathrm{~m}$ & $\mathrm{~m}$ \\
\hline freshwater_content_0-2000 & Freshwater content in the top $2000 \mathrm{~m}$ & $\mathrm{~m}$ \\
\hline freshwater_content_0-bottom & Total freshwater content & $\mathrm{m}$ \\
\hline heat_content_0-300 & Heat content in the top $300 \mathrm{~m}$ & $\mathrm{~J} \mathrm{~m}^{-2}$ \\
\hline heat_content_0-700 & Heat content in the top $700 \mathrm{~m}$ & $\mathrm{~J} \mathrm{~m}^{-2}$ \\
\hline heat_content_0-2000 & Heat content in the top $2000 \mathrm{~m}$ & $\mathrm{~J} \mathrm{~m}^{-2}$ \\
\hline heat_content_0-bottom & Total heat content & $\mathrm{J} \mathrm{m}^{-2}$ \\
\hline latent_heatflux & Latent heat flux & $\mathrm{W} \mathrm{m}^{-2}$ \\
\hline meridional_wind_stress & Meridional wind stress & $\mathrm{Nm}^{-2}$ \\
\hline mixed_layer_depth_d010 & Mixed layer depth $\left(0.10 \mathrm{~kg} \mathrm{~m}^{-3}\right.$ density criterion $)$ & $\mathrm{m}$ \\
\hline net_longwave_heatflux_downwards & Net long-wave heat flux (downwards) & $\mathrm{W} \mathrm{m}^{-2}$ \\
\hline net_shortwave_heatflux_downwards & Net short-wave heat flux (downwards) & $\mathrm{W} \mathrm{m}^{-2}$ \\
\hline net_surface_heatflux_downwards & Net heat flux (downwards) & $\mathrm{W} \mathrm{m}^{-2}$ \\
\hline net_surface_waterflux_upwards & Net water flux (downwards) & $\mathrm{kg} \mathrm{m}^{-2} \mathrm{~s}^{-1}$ \\
\hline seaice_concentration & Sea-ice concentration & $0-1$ \\
\hline seaice_meridional_velocity & Sea-ice meridional velocity & $\mathrm{ms}^{-1}$ \\
\hline seaice_thickness & Sea-ice thickness & $\mathrm{m}$ \\
\hline seaice_zonal_velocity & Sea-ice zonal velocity & $\mathrm{ms}^{-1}$ \\
\hline sea_surface_height & Sea surface height & $\mathrm{m}$ \\
\hline sea_surface_meridional_current & Sea surface meridional current & $\mathrm{m} \mathrm{s}^{-1}$ \\
\hline sea_surface_salinity & Sea surface salinity & psu \\
\hline sea_surface_temperature & Sea surface temperature & ${ }^{\circ} \mathrm{C}$ \\
\hline sea_surface_zonal_current & Sea surface zonal current & $\mathrm{ms}^{-1}$ \\
\hline sensible_heatflux & Sensible heat flux & $\mathrm{W} \mathrm{m}^{-2}$ \\
\hline zonal_wind_stress & Zonal wind stress & $\mathrm{Nm}^{-2}$ \\
\hline land_sea_mask & Land sea mask ( 1 over sea) & $0-1$ \\
\hline
\end{tabular}

Time series and integrated variables

\begin{tabular}{|c|c|c|c|}
\hline Variable name & Dimensions & Full name/meaning & Units \\
\hline ftransp & Time & Freshwater transport across selected sections* & Sv \\
\hline htransp & Time & Heat transport across selected sections* & PW \\
\hline Vtransp & Time & Volume transport across selected sections* & $\mathrm{Sv}$ \\
\hline icearea_antarctic & Time & Sea-ice area in the Antarctic region (net area of sea ice where concentration is greater than $15 \%$ ) & $\mathrm{m}^{2}$ \\
\hline icearea_arctic & Time & Sea-ice area in the Arctic region (net area of sea ice where concentration is greater than $15 \%$ ) & $\mathrm{m}^{2}$ \\
\hline iceext_antarctic & Time & Sea-ice extension in the Antarctic region (extension of sea ice where concentration is greater than $15 \%$ ) & $\mathrm{m}^{2}$ \\
\hline iceext_arctic & Time & Sea-ice extension in the Arctic region (extension of sea ice where concentration is greater than $15 \%$ ) & $\mathrm{m}^{2}$ \\
\hline icevolume_antarctic & Time & Sea-ice volume in the Antarctic region & $\mathrm{m}^{3}$ \\
\hline icevolume_arctic & Time & Sea-ice volume in the Arctic region & $\mathrm{m}^{3}$ \\
\hline amoc & Latitude, depth, time & Atlantic Ocean meridional streamfunction & Sv \\
\hline amoc_26N & Depth, time & $\mathrm{AMOC}$ at $26^{\circ} \mathrm{N}$ & \\
\hline max_amoc_26N & Time & Maximum of the $\mathrm{AMOC}$ at $26^{\circ} \mathrm{N}$ & $\mathrm{Sv}$ \\
\hline mht_a & Latitude, time & Meridional heat transport in the Atlantic Ocean & PW \\
\hline mht_g & Latitude, time & Global meridional heat transport & PW \\
\hline amoc & Latitude, depth, time & Atlantic Ocean meridional streamfunction & $\mathrm{Sv}$ \\
\hline halosteric & Time & Global halosteric sea level anomaly & $\mathrm{m}$ \\
\hline steric & Time & Global steric sea level anomaly & $\mathrm{m}$ \\
\hline
\end{tabular}




\section{The Supplement related to this article is available online at doi:10.5194/essd-8-679-2016-supplement.}

Edited by: G. M. R. Manzella

Reviewed by: two anonymous referees

\section{References}

Balmaseda, M. and Anderson, D.: Impact of initialization strategies and observations on seasonal forecast skill, Geophys. Res. Lett., 36, L01701, doi:10.1029/2008GL035561, 2009.

Balmaseda, M. A., Hernandez, F., Storto, A., Palmer, M. D., Alves, O., Shi, L., Smith, G. C., Toyoda, T., Valdivieso, M., Barnier, B., Behringer, D., Boyer, T., Chang, Y.-S., Chepurin, G. A., Ferry, N., Forget, G., Fujii, Y., Good, S., Guinehut, S., Haines, K., Ishikawa, Y., Keeley, S., Köhl, A., Lee, T., Martin, M. J., Masina, S., Masuda, S., Meyssignac, B., Mogensen, K., Parent, L., Peterson, K. A., Tang, Y. M., Yin, Y., Vernieres, G., Wang, X., Waters, J., Wedd, R., Wang, O., Xue, Y., Chevallier, M., Lemieux, J.-F., Dupont, F., Kuragano, T., Kamachi, M., Awaji, T., Caltabiano, A., Wilmer-Becker, K., and Gaillard, F.: The Ocean Reanalyses Intercomparison Project (ORA-IP), J. Oper. Oceanogr., 8, s80s97, 2015.

Barnier, B., Madec, G., Penduff, T., Molines, J. M., Treguier, A. M., Le Sommer, J., Beckmann, A., Biastoch, A., Boning, C., Dengg, J., Derval, C., Durand, E., Gulev, S., Remy, E., Talandier, C., Theetten, S., Maltrud, M., McClean, J., and De Cuevas, B.: Impact of partial steps and momentum advection schemes in a global ocean circulation model at eddy-permitting resolution, Ocean Dynam., 56, 543-567, doi:10.1007/s10236-006-0082-1, 2006.

Bellucci, A., Masina, S., Di Pietro, P., and Navarra, A.: Using temperature salinity relations in a Global Ocean implementation of a multivariate data assimilation scheme, Mon. Weather Rev., 135, 3785-3807, 2007.

Bernie, D. J., Guilyardi, E., Madec, G., Slingo, J. M., and Woolnough, S. J.: Impact of resolving the diurnal cycle in an oceanatmosphere GCM. Part 1: A diurnally forced OGCM, Clim. Dynam., 29, 575-590, 2007.

Bouillon, S., Morales Maqueda, M. A., Legat, V., and Fichefet, T.: An elastic-viscous-plastic sea ice model formulated on Arakawa B and C grids, Ocean Model., 27, 174-184, 2009.

Calvert, D. and Siddorn, J.: Revised vertical mixing parameters for the UK community standard configuration of the global NEMO ocean model, Hadley Centre Technical Note 95, 74 pp., available at: http://www.metoffice.gov.uk/media/pdf/9/0/HCTN_ 95.pdf (last access: 21 May 2014), 2013.

Carton, J. and Santorelli, A.: Global upper ocean heat content as viewed in nine analyses, J. Climate, 21, 6015-6035, 2008.

Cavalieri, D. J., Parkinson, C. L., Gloersen, P., Comiso, J. C., and Zwally, H. J.: Deriving long-term time series of sea ice cover from satellite passive-microwave multisensor data sets, J. Geophys. Res., 104, 15803-15814, doi:10.1029/1999JC900081, 1999.
Cessi, P., Pinardi, N., and Lyubartsev, V.: Energetics of Semienclosed Basins with Two-Layer Flows at the Strait, J. Phys. Oceanogr., 44, 967-979, 2014.

Church, J. A., White, N. J., and Arblaster, J. M.: Significant decadalscale impact of volcanic eruptions on sea level and ocean heat content, Nature, 438, 74-77, doi:10.1038/nature04237, 2005

Dee, D. P., Uppala, S. M., Simmons, A. J., Berrisford, P., Poli, P., Kobayashi, S., Andrae, U., Balmaseda, M. A., Balsamo, G., Bauer, P., Bechtold, P., Beljaars, A. C. M., van de Berg, L., Bidlot, J., Bormann, N., Delsol, C., Dragani, R., Fuentes, M., Geer, A. J., Haimberger, L., Healy, S. B., Hersbach, H., Hólm, E. V., Isaksen, L., Kållberg, P., Köhler, M., Matricardi, M., McNally, A. P., Monge-Sanz, B. M., Morcrette, J.-J., Park, B.-K., Peubey, C., de Rosnay, P., Tavolato, C., Thépaut, J.-N., and Vitart, F.: The ERA-Interim reanalysis: Configuration and performance of the data assimilation system, Q. J. Roy. Meteor. Soc., 137, 553-597, 2011.

Dee, D., Balmaseda, M., Balsamo, G., Engelen, R., Simmons, A., and Thépaut, J.-N.: Toward a consistent reanalysis of the climate system, B. Am. Meteorol. Soc., 95, 1235-1248, 2014.

Desroziers, G., Berre, L., Chapnik, B., and Poli, P.: Diagnosis of observation, background and analysis-error statistics in observation space, Q. J. Roy. Meteor. Soc., 131, 3385-3396, 2005.

Dobricic, S. and Pinardi, N.: An oceanographic three-dimensional assimilation scheme, Ocean Model., 22, 89-105, 2008.

Ezer, T.: Detecting changes in the transport of the Gulf Stream and the Atlantic overturning circulation from coastal sea level data: The extreme decline in 2009-2010 and estimated variations for 1935-2012, Global Planet. Change, 129, 23-36, 2015.

Fichefet, T. and Morales Maqueda, M. A.: Sensitivity of a global sea ice model to the treatment of ice thermodynamics and dynamics, J. Geophys. Res., 102, 12609-12646, doi:10.1029/97JC00480, 1997.

Good, S. A., Martin, M. J., and Rayner, N. A.: EN4: quality controlled ocean temperature and salinity profiles and monthly objective analyses with uncertainty estimates, J. Geoph. Res., 118, 6704-6716, doi:10.1002/2013JC009067, 2013.

Griffies, S. M., Danabasoglu, G., Durack, P. J., Adcroft, A. J., Balaji, V., Böning, C. W., Chassignet, E. P., Curchitser, E., Deshayes, J., Drange, H., Fox-Kemper, B., Gleckler, P. J., Gregory, J. M., Haak, H., Hallberg, R. W., Heimbach, P., Hewitt, H. T., Holland, D. M., Ilyina, T., Jungclaus, J. H., Komuro, Y., Krasting, J. P., Large, W. G., Marsland, S. J., Masina, S., McDougall, T. J., Nurser, A. J. G., Orr, J. C., Pirani, A., Qiao, F., Stouffer, R. J., Taylor, K. E., Treguier, A. M., Tsujino, H., Uotila, P., Valdivieso, M., Wang, Q., Winton, M., and Yeager, S. G.: OMIP contribution to CMIP6: experimental and diagnostic protocol for the physical component of the Ocean Model Intercomparison Project, Geosci. Model Dev., 9, 3231-3296, doi:10.5194/gmd9-3231-2016, 2016

Ingleby, B. and Huddleston, M.: Quality control of ocean temperature and salinity profiles: Historical and real-time data, J. Marine Syst., 65, 158-175, 2007.

Johns, W. E., Baringer, M. O., Beal, L. M., Cunningham, S. A., Kanzow, T., Bryden, H. L., Hirschi, J. J. M., Marotzke, J., Meinen, C. S., Shaw, B., and Curry, R.: Continuous, array-based estimates of Atlantic ocean heat transport at $26.5^{\circ} \mathrm{N}$, J. Climate, 24, 24292449, 2011. 
Kurtz, N. T. and Markus, T.: Satellite observations of Antarctic sea ice thickness and volume, J. Geophys. Res., 117, C08025, doi:10.1029/2012JC008141, 2012.

Laloyaux, P., Balmaseda, M., Dee, D., Mogensen, K., and Janssen, P.: A coupled data assimilation system for climate reanalyses, Q. J. Roy. Meteor. Soc., 142, 65-78, 2015.

Large, W. G. and Yeager, S. G.: Diurnal to decadal global forcing for ocean and sea-ice models: the data sets and flux climatologies, NCAR Technical report NCAR/TN-460, Boulder, Colorado, USA, 2004.

Lazzari, P., Solidoro, C., Ibello, V., Salon, S., Teruzzi, A., Báranger, K., Colella, S., and Crise, A.: Seasonal and inter-annual variability of plankton chlorophyll and primary production in the Mediterranean Sea: a modelling approach, Biogeosciences, 9, 217-233, doi:10.5194/bg-9-217-2012, 2012.

Levitus, S., Antonov, J. I., Boyer, T. P., Baranova, O. K., Garcia, H. E., Locarnini, R. A., Mishonov, A. V., Reagan, J. R., Seidov, D., Yarosh, E. S., and Zweng, M. M.: World ocean heat content and thermosteric sea level change (0-2000 m), 1955-2010, Geophys. Res. Lett., 39, L10603, doi:10.1029/2012GL051106, 2012.

Madec, G.: NEMO Ocean Engine. Note du Pole de modélisation 27, Institut Pierre-Simon Laplace, Paris, France, 2008.

Masina, S., Di Pietro, P., Storto, A., and Navarra, A.: Global ocean re-analyses for climate applications, Dynam. Atmos. Oceans, 52, 341-366, 2011.

Masina, S., Storto, A., Ferry, N., Valdivieso, M., Haines, K., Balmaseda, M., Zuo, H., Drevillion, M., and Parent, L.: An ensemble of eddy-permitting global ocean reanalyses from the MyOcean project, Clim. Dynam., doi:10.1007/s00382-015-2728-5, in press, 2016.

Massonet, F., Mathiot, P., Fichefet, T., Goosse, H., Beatty, C. K., Vancoppenolle, M., and Lavergne, T.: A model reconstruction of the Antarctic sea ice thickness and volume changes over 1980 2008 using data assimilation, Ocean Model., 64, 67-75, 2013.

Mayer, M., Haimberger, L., Pietschnig, M., and Storto, A.: Facets of Arctic energy accumulation based on observations and reanalyses 2000-2015, Geophys. Res. Lett., 43, 5261-5270, doi:10.1002/2016GL070557, 2016.

McCarthy, G. D., Smeed, D. A., Johns, W. E., Frajka-Williams, E., Moat, B. I., Rayner, D., Baringer, M. O., Meinen, C. S., Collins, J., and Bryden, H. L.: Measuring the Atlantic meridional overturning circulation at $26^{\circ} \mathrm{N}$, Prog. Oceanogr., 130, 91-111, 2015.

Megann, A., Storkey, D., Aksenov, Y., Alderson, S., Calvert, D., Graham, T., Hyder, P., Siddorn, J., and Sinha, B.: GO5.0: the joint NERC-Met Office NEMO global ocean model for use in coupled and forced applications, Geosci. Model Dev., 7, 10691092, doi:10.5194/gmd-7-1069-2014, 2014.

Meliá, P., Schiavina, M., Gatto, M., Bonaventura, L., Masina, S., and Casagrandi, R.: Integrating field data into individual-based models for the migration of European eel larvae, Mar. Ecol.Prog. Ser., 487, 135-149, 2013.

Menard, R.: Error covariance estimation methods based on analysis residuals: theoretical foundation and convergence properties derived from simplified observation networks, Q. J. Roy. Meteor. Soc., 142, 257-173, 2016.

Rayner, D., Hirschia, J. J.-M., Kanzow, T., Johns, W. E., Wright, P. G., Frajka-Williams, E., Bryden, H. L., Meinen, C. S., Baringer, M. O., Marotzke, J., Beal, L. M., and Cunningham, S. A.: Moni- toring the Atlantic meridional overturning circulation, Deep-Sea Res. Pt. II, 58, 1744-1753, 2011.

Reynolds, R., Smith, T., Liu, C., Chelton, D., Casey, K., and Schlax, M.: Daily high-resolution blended analyses for sea surface temperature, J. Climate, 20, 5473-5496, 2007.

Roberts, C. D., Waters, J., Peterson, K. A., Palmer, D. A., McCarthy, G. D., Frajka-Williams, E., Haines, K., Lea, D., Martin, M., Storkey, D., Blockley, E. W., and Zuo, H.: Atmosphere drives recent interannual variability of the Atlantic meridional overturning circulation at $26.5^{\circ} \mathrm{N}$, Geophys. Res. Lett., 40, 5164-5170, doi:10.1002/grl.50930, 2013.

Schweiger, A., Lindsay, R., Zhang, J., Steele, M., and Stern, H.: Uncertainty in modeled arctic sea ice volume, J. Geophys. Res., 116, C00D06, doi:10.1029/2011JC007084, 2011.

Sotillo, M., Cailleau, S., Lorente, P., Levier, B., Aznar, R., Reffray, G., Amo-Baladrón, A., Chanut, J., Benkiran, M., and AlvarezFanjul, E.: The MyOcean IBI Ocean Forecast and Reanalysis Systems: operational products and roadmap to the future Copernicus Service, J. Oper. Oceanogr., 8, s63-s79, 2015.

Stammer, D., Köhl, A., Awaji, T., Balmaseda, M., Behringer, D., Carton, J., Ferry, N., Fischer, A., Fukumori, I., Giese, B., Haines, K., Harrison, E., Heimbach, P., Kamachi, M., Keppenne, C., Lee, T., Masina, S., Menemenlis, D., Ponte, R., Remy, E., Rienecker, M., Rosati, A., Schröter, J., Smith, D., Weaver, A., Wunsch, C., and Xue, Y.: Ocean information provided through ensemble ocean syntheses, in: Sustained Ocean Observations and Information for Society, OceanObs'09, 21-25 September 2009, edited by: Hall, J., Harrison, D., and Stammer, D., ESA Publication WPP-306: 979-989, European Space Agency: Darmstadt, Germany, 2010.

Stammer, D., Cazenave, A., Ponte, R., and Tamisiea, M.: Causes for contemporary regional sea level changes, Annu. Rev. Marine Sci., 5, 21-46, 2013.

Stepanov, V., Iovino, D., Masina, S., Storto, A., and Cipollone, A.: Methods of calculation of the Atlantic meridional heat and volume transports from ocean models at $26.5^{\circ} \mathrm{N}$, J. Geophys. Res., 121, 1459-1475, doi:10.1002/2015JC011007, 2016.

Storto, A.: Variational quality control of hydrographic profile data with non-Gaussian errors for global ocean variational data assimilation systems, Ocean Model., 104, 226-241, doi:10.1016/j.ocemod.2016.06.011, 2016.

Storto, A. and Masina, S.: The CMCC Eddy-permitting Global Ocean Physical Reanalysis (C-GLORS v5, 1980-2014), links to NetCDF files, Pangea, doi:10.1594/PANGAEA.857995, 2016.

Storto, A., Dobricic, S., Masina, S., and Di Pietro, P.: Assimilating along-track altimetric observations through local hydrostatic adjustments in a global ocean reanalysis system, Mon. Weather Rev., 139, 738-754, 2011.

Storto, A., Russo, I., and Masina, S.: Interannual response of global ocean hindcasts to a satellite-based correction of precipitation fluxes, Ocean Sci. Discuss., 9, 611-648, doi:10.5194/osd-9-6112012, 2012.

Storto, A., Masina, S., and Dobricic, S.: Ensemble spread-based assessment of observation impact: application to a global ocean analysis system, Q. J. Roy. Meteor. Soc., 139, 1842-1862, doi:10.1002/qj.2071, 2013.

Storto, A., Masina, S., and Dobricic, S.: Estimation and Impact of Non-Uniform Horizontal Correlation Length-Scales for Global 
Ocean Physical Analyses, J. Atmos. Ocean Tech., 31, 23302349, 2014.

Storto, A., Masina, S., and Navarra, A.: Evaluation of the CMCC eddy-permitting global ocean physical reanalysis system (CGLORS, 1982-2012) and its assimilation components, Q. J. Roy. Meteor. Soc., 142, 738-758, 2016 a.

Storto, A., Yang, C., and Masina, S.: Sensitivity of global ocean heat content from reanalyses to the atmospheric reanalysis forcing: A comparative study, Geophys. Res. Lett., 43, 5261-5270, doi:10.1002/2016GL068605, 2016b.

Storto, A., Masina, S., Balmaseda, M., Guinehut, S., Xue, Y., Szekely, T., Fukumori, I., Forget, G., Chang, Y.-S., Good, S. A., Köhl, A., Vernieres, G., Ferry, N., Peterson, K. A., Behringer, D., Ishii, M., Masuda, S., Fujii, Y., Toyoda, T., Yin, Y., Valdivieso, M., Barnier, B., Boyer, T., Lee, T., Gourrion, J., Wang, O., Heimback, P., Rosati, A., Kovach, R., Hernandez, F., Martin, M. J., Kamachi, M., Kuragano, T., Mogensen, K., Alves, O., Haines, K., and Wang, X.: Steric sea level variability (1993-2010) in an ensemble of ocean reanalyses and objective analyses, Clim. Dynam., doi:10.1007/s00382-015-2554-9, in press, 2016c.

Taylor, K. E., Stouffer, R. J., and Meehl, G. A.: An Overview of CMIP5 and the experiment design, B. Am. Meteorol. Soc., 93, 485-498, 2012.

Tietsche, S., Notz, D., Jungclaus, J. H., and Marotzke, J.: Assimilation of sea-ice concentration in a global climate model - physical and statistical aspects, Ocean Sci., 9, 19-36, doi:10.5194/os-919-2013, 2013.

Trenberth, K. E. and Fasullo, J. T.: An apparent hiatus in global warming?, Earth's Future, 1, 19-32, doi:10.1002/2013EF000165, 2013.

Valdivieso, M., Haines, K., Balmaseda, M., Chang, Y.-S., Drevillon, M., Ferry, N., Fujii, Y., Köhl, A., Storto, A., Toyoda, T., Wang, X., Waters, J., Xue, Y., Yin, Y., Barnier, B., Hernandez, F., Kumar, A., Lee, T., Masina, S., and Peterson, A. K.: An assessment of air-sea heat fluxes from ocean and coupled reanalyses, Clim. Dynam., doi:10.1007/s00382-015-2843-3, in press, 2016.
Xue, Y., Balmaseda, M. A., Boyer, T., Ferry, N., Good, S., Ishikawa, I., Kumar, A., Rienecker, M., Rosati, A. J., and Yin, Y.: A comparative analysis of upper-ocean heat content variability from an ensemble of operational ocean reanalyses, J. Climate, 25, 69056929, 2012.

Yang, C., Masina, S., Bellucci, A., and Storto, A.: The Rapid Warming of the North Atlantic Ocean in the Mid-1990s in an EddyPermitting Ocean Reanalysis (1982-2013), J. Climate, 29, 54175430, doi:10.1175/JCLI-D-15-0438.1, 2016a.

Yang, C., Masina, S., and Storto, A.: Historical ocean reanalyses (1900-2010) using different data assimilation strategies, Q. J Roy. Meteor. Soc., doi:10.1002/qj.2936, online first, $2016 \mathrm{~b}$.

Yu, L. and Weller, R. A. : Objectively Analyzed air-sea heat Fluxes for the global ice-free oceans (1981-2005), B. Am. Meteorol. Soc., 88, 527-539, 2007.

Zhang, J. L. and Rothrock, D. A.: Modeling global sea ice with a thickness and enthalpy distribution model in generalized curvilinear coordinates, Mon. Weather Rev., 131, 845-861, 2003.

Zhang, Y., Rossow, W. B., and Stackhouse Jr., P. W.: Comparison of different global information sources used in surface radiative flux calculation: Radiative properties of the surface, J. Geophys. Res., 112, D01102, doi:10.1029/2005JD007008, 2007.

Zuo, H., Balmaseda, M., and Mogensen, K.: The new eddypermitting ORAP5 ocean reanalysis: description, evaluation and uncertainties in climate signals, Clim. Dynam., doi:10.1007/s00382-015-2675-1, in press, 2016. 